\title{
Sorting Through the Many Total-Energy-Cycle Pathways Possible with Early Plug-In Hybrids
}

\author{
Dana Meyers* \\ Kammy Willis*
}

\begin{abstract}
Using the "total energy cycle" methodology, we compare U.S. near term (to 2015) alternative pathways for converting energy to light-duty vehicle kilometers of travel (VKT) in plug-in hybrids (PHEVs), hybrids (HEVs), and conventional vehicles $(\mathrm{CVs})$. For PHEVs, we present total energy-per-unit-of-VKT information two ways (1) energy from the grid during charge depletion (CD); (2) energy from stored on-board fossil fuel when charge sustaining (CS). We examine "incremental" sources of supply of liquid fuel such as (a) oil sands from Canada, (b) Fischer-Tropsch diesel via natural gas imported by LNG tanker, and (c) ethanol from cellulosic biomass. We compare such fuel pathways to various possible power converters producing electricity, including (i) new coal boilers, (ii) new integrated, gasified coal combined cycle (IGCC), (iii) existing natural gas fueled combined cycle (NGCC), (iv) existing natural gas combustion turbines, (v) wood-to-electricity, and (vi) wind/solar. We simulate a fuel cell HEV and also consider the possibility of a plug-in hybrid fuel cell vehicle (FCV). For the simulated FCV our results address the merits of converting some fuels to hydrogen to power the fuel cell vs. conversion of those same fuels to electricity to charge the PHEV battery. The investigation is confined to a U.S. compact sized car (i.e. a world passenger car). Where most other studies have focused on emissions (greenhouse gases and conventional air pollutants), this study focuses on identification of the pathway providing the most vehicle kilometers from each of five feedstocks examined. The GREET 1.7 fuel cycle model and the new GREET 2.7 vehicle cycle model were used as the foundation for this study. Total energy, energy by fuel type, total greenhouse gases (GHGs), volatile organic compounds (VOC), carbon monoxide (CO), nitrogen oxides (NOx), fine particulate (PM2.5) and sulfur oxides (SOx) values are presented. We also isolate the PHEV emissions contribution from varying $\mathrm{kWh}$ storage capability of battery packs in HEVs and PHEVs from $\sim 16$ to $64 \mathrm{~km}$ of charge depleting distance. Sensitivity analysis is conducted with respect to the effect of replacing the battery once during the vehicle's life. The paper includes one appendix that examines several recent studies of interactions of PHEVs with patterns of electric generation and one that provides definitions, acronyms, and fuel consumption estimation steps.
\end{abstract}

Keywords: Plug-in Hybrid Electric Vehicle, Li-ion Battery, Energy Consumption, Vehicle Performance, Zero Emissions Vehicle (ZEV)

\section{INTRODUCTION}

Over the last two decades, automakers, entrepreneurs and governments have exerted considerable effort to develop alternatives to the petroleum-product-fueled internal combustion engine, in order to improve air quality, reduce oil consumption, and/or reduce greenhouse gases. Options receiving attention have included alcohol fuels, electric vehicles (EVs), hybrids (HEVs), plug-in hybrids (PHEVs), fuel cell vehicles (FCVs), and combinations of these. Further, effort to alter the mix of refined petroleum products to be usedfrom petrol in spark ignited (SI) engines toward diesel fuel in compression ignition (CI) engines - has also been intensive.

\subsection{Advanced Vehicles Dedicated to One Fuel}

During the 1990s, the possible future of electric drive was evaluated by national laboratory scientists [1-3].

*Myers Motors

180 South Avenue, Tallmadge, Ohio 44278

Ph: 330.630.3768, Fax: 330.633.0756

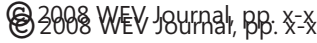

One set of evaluations included EVs, PHEVs, and FCVs [1]. Another intensive multi-laboratory evaluation focused on the $\mathrm{EV}[2,3]$. The $\mathrm{EV}$ was indirectly promoted by a regulation in California mandating zero tailpipe (TTW) emissions technology, while the diesel electric hybrid vehicle was promoted by very ambitious goals of the Partnership for a New Generation of Vehicles (PNGV). California did not get the zero TTW emissions vehicles that it mandated. Perhaps in part, the total energy cycle methodology contributed to the failure of this technology, in the sense that national well-to-wheels emissions increases of sulfur oxides (SOx), particulates (PM), and lead were projected, if the EV were to be adopted nationwide [3]. The alternative zero tailpipe emissions technology that came to the forefront, after acceptance of the improbability of the success of the EV, was the FCV. In the meantime, GHGs began to be a concern, at least from the point of view of including them in the evaluations and considerations of the technologies. The next debate involved WTW comparisons of advanced CIDI powertrain and fuel options to those for FCVs [4-9]. No 
clear multi-objective winner was identified. However, during this time interval, air quality and national vehicle tailpipe emissions regulations were tightened significantly. The PNGV project was canceled, in part because it had to rely on the diesel hybrid to achieve its fuel consumption goal, while tightened emissions standards then seemed unattainable. However, General Motors produced a prototype FCV that theoretically could meet the long term fuel consumption goals on a TTW basis, after converting the hydrogen fuel energy into "petrol equivalents". This option had the desirable feature that it could, in theory, meet both the federal goal of $\sim 3$ liters per $100 \mathrm{~km}$ petrol equivalent fuel economy in a mid-size vehicle, and also have zero tailpipe emissions. Thus, based on this promise, a focused federal program to conduct the research and development to bring this technology to market was begun.

\subsection{Advanced Vehicles Dedicated to Two Fuels - Electricity and ?}

In the meantime, a separate thread of powertrain $R \& D$ was underway. In order to hedge its bets, and enjoy the possibility of multiple technological pathways toward zero tailpipe emissions, California modified its regulations to allow some credit to be given toward its overall zero emission vehicle requirements, were a manufacturer to introduce a hybrid vehicle capable of running all electrically for 32 or more $\mathrm{km}$ (since reduced to 16). This was the plug-in hybrid (PHEV) alternative. The amount of the credit rose linearly up to a maximum, from an all electric range capability of 32 to $96 \mathrm{~km}$. This followed the development of 1990s PHEV prototypes by university teams in student competitions, co-sponsored by the U.S. auto industry and the U.S. Department of Energy. Also, in the late 1990s, both Toyota (Prius) and Honda (Insight) introduced commercial hybrid vehicles capable of significant reductions in fuel consumption compared to available passenger cars. In light of these developments, both the Electric Power Research Institute [10] and the Department of Energy's national labs [11] began evaluating PHEVs, each publishing reports on the topic in 2001. These analyses relied on the assumption that nickel metal hydride ( $\mathrm{Ni}-\mathrm{MH})$ would be the battery of choice for plug-in hybrids, since it was the battery technology succeeding in the commercial hybrids introduced by Toyota and Honda. In the meantime, the Department of Energy's energy storage program had shifted its focus toward lithium-based batteries. The lithium polymer battery had been identified by experts to be the most promising long-term option for EVs, with the lowest long-term costs achievable among the chemistries considered [12]. Soon after this study, the Department of Energy commissioned a cost evaluation of another lithium-based battery technology, lithium-ion (Li-ion), which concluded that costs for this variant could "optimistically" drop as low as $\$ 250 / \mathrm{kWh}$ for high energy (EV) batteries, and $\$ 1100$ for high power batteries [13]. The shift of emphasis proved to be prescient, as Li-ion battery technology continued to improve dramatically. Energy density of commercial $\mathrm{Li}^{-}$ ion batteries for electronics equipment continued to rise steadily, nearly doubling from 2000 to 2005 , while that of Ni-MH remained constant [14]. Meanwhile, costs of Li-ion consumer batteries (cells) dropped dramatically until they were lower than batteries using $\mathrm{Ni}-\mathrm{MH}$ and nickel-cadmium (Ni-Cd) chemistries [15].

As a result of the 2001 studies of PHEVs [10, 11], and advocacy by many enthusiasts, a number of studies of the potential interactive effects of PHEVs and the electric grid have since been conducted. These studies, largely independently initiated, emerged in recent years [16-24], concentrating on the US electric grid. Their general implications for electric generation mix and type of power plant construction over the next few decades are discussed in Appendix A.

This paper compares energy use and emissions for selected individual pathways from primary energy source to vehicle kilometers for the period from the present to 2015, drawing on the review of longer term studies. The review in Appendix A provides additional discussion, beyond that in section 4 , concerning reasons that particular electric generation pathway choices have been included or excluded. The power generation and power plant construction projections made for this paper assume no carbon regulation or taxation. A companion paper [25] addresses methods of estimating aggregate long-term oil savings potential from PHEVs.

\subsection{Terminology.}

Terms used (acronyms) in this paper can be found in Appendix B. Information on the adjustment of simulated PHEV fuel and electricity consumption from "certification test" to "on-road" fuel consumption, required by the GREET model, is also provided.

\section{METHODOLOGY}

\subsection{GREET 2.7 Within the Conceptual Life Cycle Analysis Framework}

Life-cycle analysis (LCA) is a useful technique for comparing alternative technological options, and can take several forms. A complete life-cycle analysis includes not only an inventory of the energy use and emissions for a well-defined system, but also an estimate of the impacts made on the environment and population, the procedure for which is not yet wellestablished. This paper reports the results of an inventory analysis for the system that encompasses primary fuels and vehicle materials in the ground through vehicle use and recycling. Another name for this sort of analysis is total energy cycle analysis. The total energy cycle includes the fuel cycle (well-to-wheels, WTW), comprised of two parts, the well-to-pump (or 
plug) (WTP), and (plug or) pump-to-wheel (PTW) steps, and the vehicle cycle. Due to the observation that the vehicle cycle (vehicle material production, fabrication, assembly, disassembly, and recycling) contributes a significant fraction of total energy use and emissions, Argonne scientists have added the vehicle cycle to the GREET 1.7 full fuel-cycle model, creating the GREET 2.7 version [26].

In this type of process analysis one would in theory need to also account for the energy embedded in production and recycling of each piece of capital (physical) equipment used in the process. However, it was determined early in the history of LCA that the energy infrastructure produces far more output per year and also lasts many more years than does an automobile, so over its lifetime the contribution of WTP infrastructure to each unit of automotive service is generally negligible. Were a particular case to violate this rule, Input/Output ( $\mathrm{I} / \mathrm{O})$ is one analytical tool that can be used. Unfortunately, although I/O analysis both theoretically and statistically accounts for these secondary effects, in practice it has the serious drawback that it is fundamentally backward looking. This requires analysts to do intensive modifications of I/O models when technologies of the future are being evaluated. In addition, I/O accounting is done in dollars, which must then be converted to energy units.

Energy use to assemble and recycle batteries has received considerable attention. This is partly because batteries may require replacement during the vehicle's lifetime, although one R\&D goal for PHEV batteries is to last the entire vehicle life [27]. Results will be presented with and without battery replacement.

\subsection{Affect of Assumed 2015 Time Frame on Technology Choices}

The time frame of this study is nominally limited to the year 2015. The working assumption about PHEVs might be regarded as pessimistic by some. We assume that PHEVs could be introduced by 2010 at the earliest. If the degree of success of PHEVs were to be similar to HEVs in the U.S., this would mean that only one to two percent of new vehicle sales would be PHEVs in 2015. The share of PHEVs in the total on-road fleet would be far lower. Thus, we do not anticipate that PHEVs would have a significant effect on the grid or mix of power plants in this time frame. We see this period of time as one of evaluation of relatively small numbers of PHEVs and FCVs, to be compared to the benefits of implementing two other petroleum saving powertrain technologies, HEVs and diesels.

The power plant types evaluated are (1) evolutionary examples of widely available generation technologies that are seen as most likely to be built in the next few years regardless of success of PHEVs (2) new generation technologies for which there are relatively few units, but a few units are, or will be operating in 2015, and (3) wind, in part because it is rapidly expanding [28], and in part because some analysts have estimated that PHEVs and wind will have positive, synergistic interactions $[16,17]$.

A notable decision was to leave nuclear power for PHEVs out of the set of options evaluated, due in part to the anticipation that too many issues need to be resolved to anticipate an expansion of nuclear power to provide services to $\mathrm{PHEV}$ s in the 2015 time frame. We do not presume the existence of a strong carbon-control policy in 2015. In their recent evaluation of GHGs from much longer term, high market share implementation of PHEVs, the Electric Power Research Institute (EPRI) and Natural Resources Defense Council (NRDC), listed new nuclear power generation as unavailable even in 2030 in the absence of a carbon-control policy. Nuclear only entered the two scenarios with carbon control [24]. However, the absence of nuclear power from this paper does not indicate a lack of interest in the technology. For a paper with a longer time frame, and/or assumption of aggressive carbon control in U.S. public policy, nuclear would certainly be included.

Another notable decision is to leave out the diesel hybrid. This decision is based on the absence of commitment by any automakers to bring such a technology into the U.S. market. Nominal commitments to more petrol HEVs, to some petrol PHEVs and to additional conventional light-duty diesels certainly do exist. Nevertheless, like nuclear, this is a technology that should be considered in a longer time frame.

It is our intention in this paper to emphasize results for energy by feedstock type (re: which pathway will provide the most vehicle kilometers of service from a given feedstock?) and petroleum, so these are listed first in our results tables. We provide GHGs and criteria pollutant emissions estimates as well.

\subsection{Modeling of the Total Energy Cycle}

The GREET 1.7 and 2.7 models are is used in this investigation [26]. Versions of the GREET model have historically been widely used for comparative evaluations of full fuel cycle vehicle powertrain technology options. The full fuel cycle includes emissions and energy consumption going back to the point of origin of the fuel. For solar "fuels," it goes back to the substance or technology that originally captured and converted the sun's energy. Thus, the energy in wood chips and corn is counted, but not the solar energy that was originally converted. The energy after conversion by wind generators is counted, not the energy in the wind passing the blades of the wind generator. In any case, from these system boundaries forward until vehicle kilometers of travel have been provided, GREET has historically totaled up emissions 
and energy use by type, for specific vehicle and fuel technology combinations. This paper includes a step beyond the historical full fuel cycle analysis, adding the effects of vehicle manufacturing and disposal - the vehicle cycle [26].

The GREET model deviated from typical full fuel cycle models in that its estimates of emissions of criteria pollutants are separated into urban and upstream components. This has been done because the GREET developers recognized that probability of population exposure to pollutants is a very important criterion. This feature of GREET is not implemented in this paper.

\subsection{Vehicle Modeling}

To characterize vehicle fuel consumption, we use the Powertrain System Analysis Toolkit (PSAT), a state-of the-art flexible and reusable simulation package developed by Argonne National Laboratory and sponsored by the U.S. Department of Energy (DOE) [29]. PSAT was designed to serve as a single tool that can be used to meet the requirements of automotive engineering throughout the development process from modeling to control. PSAT is a forward-looking simulation package that follows any standard or custom driving cycle, sending a power demand to the vehicle controller, which, in turn, sends a demand to the propulsion components. Component models react to the demand and feed back their status to the vehicle controller, and the process iterates at low frequency to achieve the desired result. Light-, medium-, and heavy duty vehicles can be simulated using the large library of component data.

\section{VEHICLE CHARACTERIZATION AND FUEL CONSUMPTION ESTIMATION.}

The powertrains characterized include (1) petrol, (2) diesel (3) HEV (4) PHEV, (5) FCV. The HEV and PHEV are "full hybrids" using the split powertrain architecture, discussed below. Both cut fuel flow off during vehicle stop and deceleration. The FCV is a series hybrid, with a small battery. It does not include elimination of hydrogen flow during idle or deceleration. Relative to the split-hybrid powertrains in the HEV and PHEV, for the FCV the absence of fuel flow cutoff penalizes urban fuel consumption, while series electric drive penalizes highway fuel consumption, offsetting the relatively high efficiency of the fuel cell.

One of the conventions adopted in GREET 2.7 for the engine cases is to identify "spark ignited internal combustion engines", as SI ICEs. Fuels that are burned in such engines and are examined in this study are (1) petrol, identified in tables as conventional gasoline (CG) and reformulated gasoline (RFG) (2) a blend of ethanol ( $85 \%$ by volume) and petrol (E85), and (3) compressed natural gas (CNG). SI ICEs simulated in this study do not use turbocharging. However, the turbocharged compression ignition engine technology using direct injection, labeled CIDI, is the "diesel" engine technology simulated. Fuel types addressed for the CIDI include (1) low sulfur diesel from conventional crude oil (LSD), (2) natural gas-to-liquids (GTL) production via the Fischer-Tropsch process (FTD), and (3) coal-to-liquids (CTL) via FTD.

The fuel consumption values used in GREET are "on" road" fuel consumption values, which are higher than certification test fuel consumption. The method of adapting our certification-test based vehicle simulation results to on-road fuel consumption are discussed in Appendix B.

The vehicles simulated for this study are all based on a Prius "glider" (body) as a reference point. Holding the mass of the body constant, powertrains are switched within the same vehicle platform. Performance requirements specified assure that each vehicle can meet typical expectations of world consumers, with the exception that no towing requirement was specified. As a result, the performance requirements specified allow a reduction of engine $\mathrm{kW}$ in the HEV and PHEV cases (Table 1). This favors the HEV and PHEV a bit relative to the diesel, which is capable of providing high torque sustainable for long periods, while the battery in an HEV can boost torque only for short periods of time. The vehicles are compared assuming the same annual kilometers driven for each. While some analysts deviate from this assumption, we argue that the investigation should address the needs of an individual household, looking for powertrain alternatives for a vehicle that they intend to drive in a similar way regardless of powertrain.

Our investigation implicitly focuses on metropolitan area driving, not rural and high-speed, limited access motorway driving. The fuel consumption estimates compiled for this study represent a weighted average of urban and suburban driving within metropolitan areas. Thus, our simulations are not appropriate for drawing conclusions on energy, fuel use, and emissions for vehicles that are typically driven at relatively high speed on rural arterial roads and/or limited access highways. Since it is our judgment that the diesel powertrain has its greatest comparative advantage in such driving, we therefore highlight this limitation of the study. Diesels, as purchased, realize considerably greater annual use than petrol vehicles. The reason this is so, is that those households that drive many kilometers per year tend to choose the diesel, while those who drive less kilometers per year, in more urban conditions, tend to choose petrol. Allowing for the fact that consumers tend to spend between one and two hours per day in vehicles, on average (see Vyas et al. [25]), the only way that the tens of thousands of kilometers per year (needed to justify diesel purchases) 


\begin{tabular}{|c|c|c|c|c|c|c|c|}
\hline Vehicle type ${ }^{\wedge}$ & Diesel & Petrol & Fuel cell & $\begin{array}{c}\text { Power- } \\
\text { split }\end{array}$ & $\begin{array}{c}\begin{array}{c}\text { Power- } \\
\text { split }\end{array} \\
\end{array}$ & $\begin{array}{c}\begin{array}{c}\text { Power- } \\
\text { split }\end{array} \\
\end{array}$ & $\begin{array}{c}\begin{array}{c}\text { Power- } \\
\text { split }\end{array} \\
\end{array}$ \\
\hline Hybrid type & $\mathrm{CV}$ & $\mathrm{CV}$ & $\mathrm{HEV}$ & $\mathrm{HEV}$ & PHEV10 & PHEV32 & PHEV64 \\
\hline Accessory power (W) & 400 & 400 & 220 & 220 & 220 & 220 & 220 \\
\hline Mass (kg) & 1445 & 1389 & 1543 & 1516 & 1541 & 1566 & 1619 \\
\hline Prime power unit peak $\mathrm{kW}$ & 85 & 97 & 87 & 68 & 69 & 70 & 72 \\
\hline Motor peak power $(\mathrm{kW})$ & & & 103 & 57 & 56 & 57 & 58 \\
\hline Generator peak power $(\mathrm{kW})$ & & & & 54 & 55 & 56 & 57 \\
\hline Battery charge power $(\mathrm{kW})$ * & -1.3 & -1.3 & -31 & -32 & -71 & -71 & -71 \\
\hline Battery discharge power $(\mathrm{kW}) *$ & 0.8 & 0.8 & 35 & 37 & 63 & 63 & 63 \\
\hline Battery capacity $(\mathrm{kWh})$ & 0.8 & 0.8 & 1.3 & 1.4 & 4.2 & 8.4 & 17 \\
\hline Battery mass $(\mathrm{kg})$ & 23.8 & 23.8 & 41.9 & 43.9 & 49.6 & 76.4 & \\
\hline
\end{tabular}

Table 1. Attributes of Vehicles Simulated

^ Every vehicle has the same drag area of 0.493 square meters (1.97 sq. m. frontal area times 0.25 coefficient of drag) and the same two rolling resistance equation coefficients $(\mathrm{Crr}=0.008$; $\mathrm{Crr} 2=0.00012)$

* For the PHEVs, the power rating is the 10s power rating at 30\% SOC. For the HEVs and conventional vehicles, this is the rated power at $70 \% \mathrm{SOC}$

can be accumulated by normal households is to drive at higher average speeds than are consistent with this study's evaluations. Since our comparisons are based on an assumption of consistent average annual kilometers of driving, the fact that diesels are selectively chosen by those who drive more kilometers per year than those who buy petrol vehicles suggests that multiple comparisons, using appropriate patterns of driving for different circumstances, are desirable.

A related issue is that a PHEV will use the battery in charge depleting (CD) modes primarily within a limited distance from the point of charging, assumed here to be overnight charging at the residence. Longer trips, at sustained high speeds, especially those between cities will be completed in charge sustaining (CS) mode. Thus we have the challenge of estimating the proper mix of UDDS and HWY kilometers to assume for CD vs. CS operation (see acronym explanations in Appendix B). This will have an impact on the estimates of the benefits of use of the PHEV battery in CD mode.

In fact, we have taken one step in this direction in this paper. Charge depleting (CD) operation has been weighted at $63 \%$ urban driving, while charge sustaining (CS) and conventional vehicle operation has been weighted at 55\% (see Appendix B and Vyas et al. [25]). This paper takes only a first step toward construction of comparisons of driving pattern in which the "best" driving pattern for a particular powertrain technology is chosen, and the competing technologies are evaluated under the same set of conditions. Thus, future work addressing strengths and weaknesses of PHEVs will attempt to isolate and compare powertrains on the basis of metropolitan area PHEV CD operation, metropolitan PHEV CS operation, and rural/motorway PHEV CS operation. Note that in the latter case we anticipate the battery pack to be of little value. The diesel powertrain should fare much better in the latter type of comparison than it does under the driving assumptions used here.
Multiple weighted averages for annual driving, related to place of residence (metropolitan vs. non-metropolitan, in particular), are also desirable in future work.

Each of the vehicles has some improvements in components relative to today's vehicles. The CD behavior of the PHEV is simulated to be about $12 \%$ better than estimated for a conversion of today's Prius to a PHEV. CS fuel consumption is about $20 \%$ less. The decision to simulate the fuel cell without turning the fuel cell off at idle (eliminating hydrogen flow) was made because it anticipated that reliability of 2015 fuel cells with stop-start will not be adequate. We estimated that both the baseline and advanced technologies improve over the period of interest (recent EPRI/NRDC reports on potential environmental effects of PHEVs assume similar percent improvement [23, 24]). While the diesel PHEV might be introduced in Europe by 2015 (though high cost is an issue, [30]), we deduced that it was not likely to be introduced in the U.S. in that time frame. At the present time, some U.S. manufacturers are equivocating about introduction of the diesel powertrain in passenger cars due to the fact that $\mathrm{NOx}$ emissions regulations in the U.S. require $1 / 5$ of the NOx values required in Europe [31]. Accordingly, introduction of a diesel powertrain technology in Europe does not assure that it will also be introduced in the U.S.

\section{DISCUSSION OF PATHWAYS}

This section discusses the specific technology pathways, and estimates energy use and emissions for each. It also further discusses reasons for inclusion of these and exclusion of other pathways, and provides some context concerning the relative likelihood of various paths. Of course, the actual emissions and energy use will be from a mix of technologies that depends on public policy with regard to cap and trade NOx and SOx emissions, and fuel taxation to support 


\begin{tabular}{|l|l|l|l|l|}
\hline \multicolumn{1}{|c|}{ Refined Oil } & \multicolumn{1}{c|}{ Natural Gas } & \multicolumn{1}{c|}{ Coal } & \multicolumn{1}{c|}{ Farmed Trees } & \multicolumn{1}{c|}{ Wind/Solar } \\
\hline $\begin{array}{l}\text { Industry-average } \\
\text { petrol, for SI ICE or } \\
\text { Li-ion PHEV (CS) }\end{array}$ & CNG, for SI ICE & $\begin{array}{l}\text { CTL (FTD), for } \\
\text { CIDI }\end{array}$ & $\begin{array}{l}\text { Ethanol (E85), for } \\
\text { SI ICE FFV }\end{array}$ & $\begin{array}{l}\text { Electricity Li-ion } \\
\text { PHEV (CD) }\end{array}$ \\
\hline $\begin{array}{l}\text { Oil sands produced } \\
\text { in situ, (upgraded } \\
\text { with H2 from NG), } \\
\text { for SI ICE }\end{array}$ & FTD, for CIDI & $\begin{array}{l}\text { Electricity from } \\
\text { current average } \\
\text { coal boiler Li-ion } \\
\text { PHEV (CD) }\end{array}$ & $\begin{array}{l}\text { Ethanol (E85) Li- } \\
\text { ion PHEV FFV } \\
\text { (CS) }\end{array}$ & $\begin{array}{l}\text { H2 via electrolysis } \\
\text { FCV }\end{array}$ \\
\hline $\begin{array}{l}\text { Oil sands via surface } \\
\text { mining, (upgraded } \\
\text { with H2 from NG), } \\
\text { for SI ICE }\end{array}$ & $\begin{array}{l}\text { Electricity via ex- } \\
\text { isting simple-cycle } \\
\text { turbines Li-ion } \\
\text { PHEV (CD) }\end{array}$ & $\begin{array}{l}\text { Electricity from } \\
\text { new coal boiler Li- } \\
\text { ion PHEV (CD) }\end{array}$ & $\begin{array}{l}\text { Electricity from } \\
\text { boiler Li-ion PHEV } \\
\text { (CD) }\end{array}$ & \\
\hline $\begin{array}{l}\text { Industry average } \\
\text { petrol, for Ni-MH SI } \\
\text { ICE hybrid (HEV) }\end{array}$ & $\begin{array}{l}\text { Electricity via ex- } \\
\text { isting combined- } \\
\text { cycle plants Li-ion } \\
\text { PHEV (CD) }\end{array}$ & $\begin{array}{l}\text { Electricity from } \\
\text { IGCC Li-ion PHEV } \\
\text { (CD) }\end{array}$ & $\begin{array}{l}\text { Electricity from } \\
\text { combined cycle via } \\
\text { synthesis gas Li- } \\
\text { ion PHEV (CD) }\end{array}$ & \\
\hline $\begin{array}{l}\text { Industry-average } \\
\text { diesel, for CIDI }\end{array}$ & $\begin{array}{l}\text { H2 from SMR } \\
\text { PHEV FCV (CS) }\end{array}$ & & & \\
\hline $\begin{array}{l}\text { Electricity from ex- } \\
\text { isting oil-fired boiler, } \\
\text { for Li-ion PHEV } \\
\text { (CD) }\end{array}$ & & & & \\
\hline
\end{tabular}

Table 2: Pathways to be examined

(1) revenue increases (2) oil use penalties to enhance national security, (3) carbon taxation, or a combination of the above. Regulation under consideration as of the writing of this paper, such as renewable portfolio standards, may also play a role and would change the projected future mix of generation. But only by separating the effects of the different pathways can appropriate policy be formulated. A summary of pathways included is shown in Table 2 .

Our discussion includes three major important areas - (1) method of generation of electricity, (2) method of production of fuels, and (3) vehicle cycle issues with attention to batteries for PHEVs.

\subsection{Electricity Generation}

\subsubsection{Electricity generation from coal in comparison to other feedstocks}

Figure 1, developed as an illustration by Shelby and Mui [20], provides an introductory illustration concerning the type of generation that might be used to provide electrical energy for a PHEV. It shows the "diurnal" pattern of demand for a hypothetical day. Hadley [18] shows

multiple weekly profiles of total demand by time of day for each of the four seasons (not presented here). His illustrations show that Fig. 1 is not typical. The closest pattern in Hadley's set of four seasons is for the summer. Sharp summer peaks are caused by air conditioning demand. Contrary to Fig. 1, the peaks occur late afternoon and early evening.
Hadley assumed both unconstrained and constrained charging and tested their effects.

Under unconstrained charging the charging period begins as soon as the vehicle is plugged in. Hadley's assumptions had the vehicle returning to the garage and being plugged in during the early evening. Given the size of the battery pack and range of PHEV assumed, charging only took a few hours. Accordingly, Hadley's charging times went down the side of the overnight diurnal trough. With unconstrained charging his estimates of natural gas use were highest.

For constrained charging, there would be a timer on the charger, or the household would delay plugging in due to reduction of prices at a later hour. Since this strategy delays the onset of charging, it can lead to far more coal and less natural gas being used, which was what Hadley estimated for his constrained cases.

Kintner-Meyer et al. assumed that PHEVs would charge in such a way that all troughs would be completely filled. The dotted line illustrates their working assumption, designed to test how many PHEVs might theoretically be charged by existing power plants. One can see that, for the example in Fig. 1, they would have estimated that the majority of power would be supplied by natural gas.

Another short term consideration for electric utilities is the effect of the existence of the caps on SOx and NOx emissions [18, 23]. Despite the fact that Kintner-Meyer et al. contend that their paper "determines the upper 


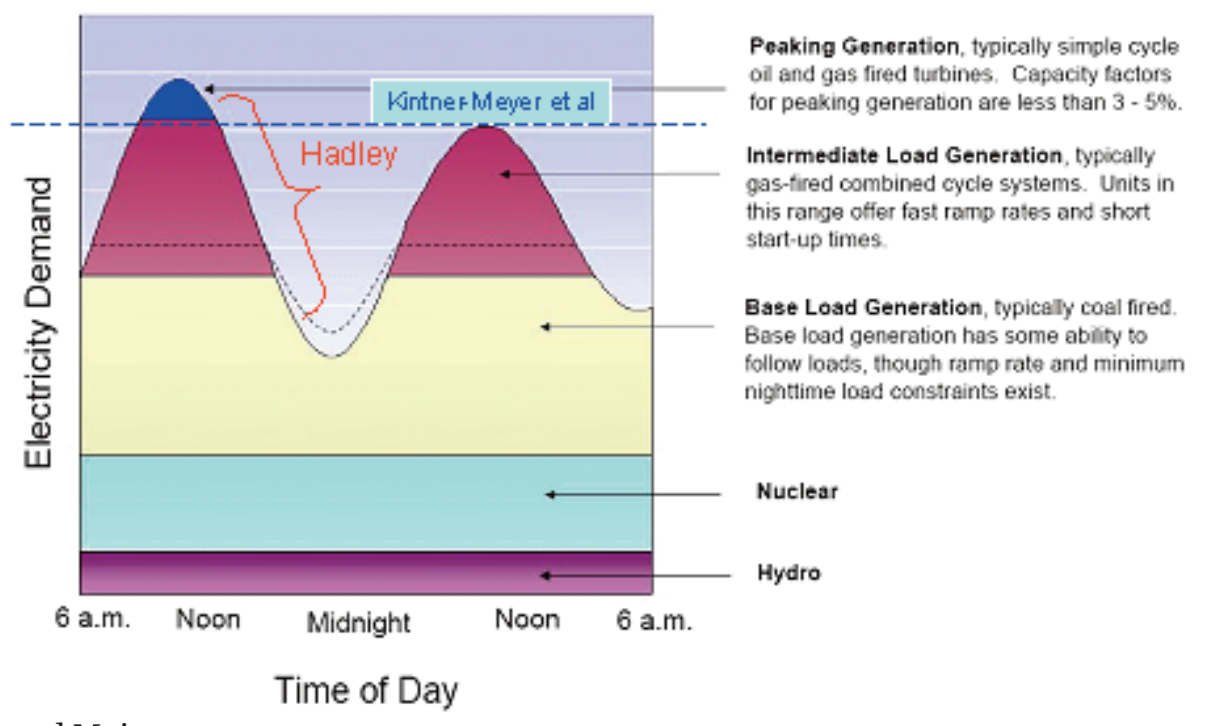

Source: Shelby and Mui, 2007

Figure 1: Typical summer load profile and dispatch scheme for many U.S. utilities [18,19, 20]

limit of the PHEV penetration without requiring new investment in generation and T\&D capacity expansions", the statement is incorrect with respect to generation. In fact, due to emissions caps on SOx and NOx, it is not possible for electric utilities to simply run existing power plants more hours per year with no related investment. The analysis in the Knipping and Duvall study [23] shows that it is necessary to invest both in cleaner new coal fired power plants, and to retrofit existing coal fired power plants with emissions control devices such as scrubbers and flue gas desulfurization. Purchase shifts toward more costly low sulfur coal may also be necessary. Balash et al. also estimated a much more rapid installation of new coal fired power plants when PHEVs entered the market than in their base case [16]. Short and Denholm estimated an early pulse, immediately after PHEV introduction, of scrubber installation on old coal fired power plants [17]. Thus, expansion of electricity demand by PHEVs is limited by emissions constraints which require investment to address. Since idle natural gas power plants are much cleaner than idle coal fired power plants, the initial load increases due to PHEVs are somewhat more likely to be provided by natural gas, until investment plans can be made to develop new clean coal powerplants and retrofit existing coal power plants.

This means that for the near term, it is reasonable to consider that PHEVs will be charged by a mix of electricity from the typical or average emissions retroffited coal-fired plants (efficiency $34.1 \%$, or 10,000 $\mathrm{Btu} / \mathrm{kWhe}$ heat rate, new coal fired power plants at an estimated efficiency of $38 \%$ [32], and/or natural gas combined cycle (IGCC) plants at 55\%). Taken together, absent strong and prompt policy shifts, the studies reviewed imply a 2015 mix of generation for PHEVs in
CD mode dominated perhaps in similar parts by combined cycle natural gas, low NOx and SOx emitting (and/or emissions control retrofitted) existing coal plants, and some new conventional technology coal plants. Wind and biomass would likely provide a smaller share than any of these three, but could provide a few percent in some locations. Simple cycle combustion turbines would provide the smallest share, but provide important emergency back up (see Appendix A).

\subsubsection{Electricity generation from natural gas}

Modern combined-cycle natural gas-fueled power plants are efficient, but domestic natural gas supply is limited. The U.S. would need numerous LNG facilities and an assured long-term supply to enhance energy security relative to oil use. Although there are now concerns that Russia, the world's leader in natural gas reserves, would not be a reliable supplier, there was early optimism about Russia's natural gas rich economy, and a wave of combined cycle natural gas-fired power plants was recently completed in the U.S. These can be expected to supply some of the power for early PHEVs, but we do not think that natural gas can be expected to be their primary long-term source of fuel. To the extent that natural gas is used for a significant fraction of generation over the next couple of decades for PHEVs, as projected in three studies [18, 19, 20], we would anticipate that the generation capacity will not be new, but existing plants, possibly used more intensively (see section 1.4). Based on judgment developed from the Shelby and Mui projection [20] and the Knipping and Duvall study [23], we include estimates for contemporary natural gas-fired power plants, but not advanced design plants. Note, however, that for a carbon constrained case (which we do not assume), the 
Duvall and Knipping study did predict that advanced combined cycle natural gas plants would be added [24].

\subsubsection{Electric generation from wind}

This option was included because it figures prominently in other studies [16, 17], and expands in share in the Duvall and Knipping carbon constrained case [24]. The former two studies assert a positive synergism between wind and PHEVs, due to beneficial effects of energy storage and fortuitous timing of wind power and overnight charging needs. Further, though from a small base, wind generation is expanding rapidly [28].

\subsubsection{Electricity generation from woody biomass and wind/solar energy}

Commercial plants currently produce electricity from both wood and wood waste, and existing legislation and proposed bills provide incentives for generation of electricity from both closed loop (dedicated energy crops) and open loop (clean forest and other wood wastes) biomass. Wind and woody biomass incentives are both receiving considerable attention in proposed federal legislation [32, Appendix E]. Thus, it seemed appropriate to include these methods of generating electricity for direct use, and also the logical competitive uses of renewable energy for provision of kilometers of service - i.e. ethanol from farmed trees and hydrogen via electrolysis from wind power. Both direct combustion and integrated gasification combined-cycle options are included.

In light of the use of renewable portfolio standards for petrol, and the possibility of renewable portfolio standards or other incentives for electric generation, the question of best use of biomass to provide motive power arises. In particular, is it better to convert woody cellulosic biomass to ethanol for use in FFV PHEVs, or would it be better to burn that biomass in a power plant to provide electricity to move the PHEV? Note that the Energy Policy Act of 2005 [35] directed the U.S. Department of Energy to examine the desirability of PHEV FFVs, so this question is quite pertinent. Woody biomass (farmed trees) is the feedstock-of choice in order to obviate both food-fuel competition, and further discussion of corn-based ethanol's energy balance.

Nominally, photovoltaic solar power is not included due to high cost. None of the studies reviewed indicated significant amounts of solar power, even with high PHEV penetration. However, results for photovoltaic solar would be essentially the same as wind, since we do not include energy and emissions in construction and demolition of long-lived physical energy conversion equipment in the computations.

\subsection{Fuel Pathways}

\subsubsection{Fuels refined from conventional crude oil and Canadian oil sands}

Fuels refined from conventional crude oil include low sulfur diesel (LSD), and petrol. The petrol characterized is a weighted average of reformulated petrol and conventional petrol.

Incremental sources of hydrocarbons for refineries are dropping in quality, and future supplies will rely ever more heavily on bitumen from Canadian oil sands. It takes considerable energy to upgrade bitumen to a suitable refined product that can be used in vehicles. Hydrogen is also required, here assumed to be produced by steam reforming of natural gas. In the long term, this H2 could be supplied by nuclear power [33]. Our analysis includes an estimate of petrol production from surface mining of oil sands, and a method of underground extraction involving heating of the oil sands (in situ production).

Thus, although we present estimates for average crude oil, we also present estimates for Canadian oil sands as well, for purposes of comparison.

\subsubsection{Natural gas to distillate (diesel) and other fuels}

The Fischer-Tropsch process for converting synthesis gas to a high-quality fuel equivalent to petroleum distillate has been known since WWII, when the Germans first used it to produce fuels from coal. In recent times, South Africa produced distillate from coal when sanctions were imposed on it due to Apartheid. Natural gas is currently converted to distillate (FischerTropsch Diesel, or FTD) at several locations worldwide, with Qatar, in the Persian Gulf, the leading producer. This process is included here, for use in a CIDI engine for which it is suited.

A process to convert natural gas to petrol via methanol was developed in the 1980s, and implemented in New Zealand, but it is very undesirable from the perspective of greenhouse gas production [34]. The methanol production step alone is similar in energy intensity to FTD. In addition, petrol and methanol are best used in a spark ignition, which is less efficient than a CIDI engine. Production of FTD from natural gas for use in CIDI engines is thus far superior to production of petrol from natural gas to use in spark ignition (SI) engines, and we have excluded the NG-to-petrol SI pathway.

\subsubsection{Natural gas to hydrogen by steam methane reforming}

Although hydrogen can be derived from a variety of energy sources, including fossil fuels, biomass, or electricity (from solar, wind, nuclear, etc.), near-term production will likely be based on technologies in place today. Therefore, for the 2015 time frame, it was 
assumed that hydrogen would be derived from steam reforming (SMR) of natural gas, which is the source of almost all of current production. Furthermore, it was decided to use the option in GREET in which production is done in small, decentralized SMR plants, rather than in large, centralized production plants Although centralized production is more efficient, it requires the construction of significant hydrogen pipeline infrastructure and the demand for high production volume, neither of which seems likely by 2015 . In the longer term, centralized production and production from low-carbon sources, such as wind and nuclear power, might gain importance.

\subsubsection{Compressed natural gas}

Natural gas is used in many locations in both sparkignition and compression-ignition engines. Generally, when used in compression-ignition engines, it is used with distillate as a "pilot ignition" fuel. In the analysis for this paper we only characterize the use of compressed natural gas (CNG) in a SI engine. Honda sells such a powertrain in the U.S. in the Honda Civic GX. For the U.S. case, we assume that the natural gas is imported via LNG tanker.

\subsubsection{Coal to liquids}

Since coal used in the coal-to-liquids (CTL) process has a higher carbon-to-hydrogen ratio than does natural gas, this feedstock is even more likely to be converted to distillate fuels than to lighter fractions (i.e. petrol) than is natural gas. Thus, this WTP pathway is matched to the CIDI powertrain technology.

Although there have been proposals to use biomass as a co-feedstock with coal, to increase the proportion of hydrogen in the synthesis gas and increase the quantity of diesel fuel produced, we have not included this option.
These processes are not well characterized in GREET.

\subsubsection{Farmed trees to ethanol}

Woody biomass (farmed trees) is the feedstock-of choice in order to obviate both food-fuel competition, and further discussion of corn-based ethanol's energy balance. In light of the use of renewable portfolio standards for petrol, and the possibility of renewable portfolio standards or other incentives for electric generation, the question of best use of biomass to provide motive power arises.

\section{RESULTS}

\subsection{Most Favorable Pathways for Each Feedstock}

In this section, we compare all of the available pathways from each feedstock for supplying vehicle kilometers, on the basis of total energy, fossil fuel use, and emissions. In almost every case, one path stands out as optimal on the basis of most, if not all criteria. This path represents the most favorable use of this feedstock (highlighted in yellow), and it will be compared against the most favorable paths from the other feedstocks. The cases for which the battery is assumed to require a replacement during the vehicle's service life are chosen here primarily to avoid giving the early 2015 PHEV options a possibly undeserved advantage.

\subsubsection{Refined oil pathway comparison}

Table 3 summarizes energy inputs and emissions for each of the pathways using refined oil as their feedstock. The most energy is used by the oil sands pathways, which both add natural gas to upgrade the feedstock. The oil-fired boiler power plant shows high SOx

\begin{tabular}{|c|c|c|c|c|c|c|c|}
\hline $\begin{array}{l}\text { Pathways } \\
\rightarrow 1000 \text { s of } \\
\text { joules } / \mathrm{km}\end{array}$ & $\begin{array}{c}\text { SI ICE Oil } \\
\text { Sands In } \\
\text { Situ }\end{array}$ & $\begin{array}{c}\text { SI ICE Oil } \\
\text { Sands Sur- } \\
\text { face Mining }\end{array}$ & $\begin{array}{c}\text { SI ICE } \\
\text { CG/RFG }\end{array}$ & CIDI LSD & $\begin{array}{c}\text { PHEV CD } \\
\text { Boiler }\end{array}$ & $\begin{array}{l}\text { PHEV CS } \\
\text { CG/RFG }\end{array}$ & $\begin{array}{c}\text { SI HEV } \\
\text { RFGw/NiM } \\
\text { HBattery } \\
\end{array}$ \\
\hline Total Energy & 4,045 & 3,772 & 3,490 & 3,104 & 2,955 & 2,565 & 2,409 \\
\hline Petroleum & 2,723 & 2,725 & 2,725 & 2,529 & 2,412 & 1,844 & 1,749 \\
\hline Natural gas & 913 & 617 & 368 & 314 & 278 & 344 & 322 \\
\hline Coal & 264 & 281 & 254 & 233 & 229 & 265 & 241 \\
\hline \multicolumn{8}{|l|}{ Grams/km } \\
\hline $\mathrm{GHG}_{\mathrm{s}}$ & 290 & 283 & 257 & 240 & 242 & 191 & 180 \\
\hline VOC & 0.288 & 0.287 & 0.285 & 0.182 & 0.148 & 0.238 & 0.235 \\
\hline $\mathrm{CO}$ & 2.352 & 2.348 & 2.347 & 0.505 & 0.23 & 2.358 & 2.354 \\
\hline NOx * & 0.209 & 0.196 & 0.196 & 0.184 & $0.502(0.37)$ & 0.164 & 0.157 \\
\hline PM2.5 & 0.039 & 0.04 & 0.036 & 0.035 & 0.033 & 0.037 & 0.035 \\
\hline $\mathrm{SOx} *$ & 0.138 & 0.141 & 0.14 & 0.131 & $1.434(1.21)$ & 0.223 & 0.186 \\
\hline
\end{tabular}

Table 3: Refined oil pathway energy use and emissions (1 battery replacement)

* According to ref. 21, when utility NOx or SOx emissions caps exist, GREET estimates of upstream emissions will in practice be reduced by the power plant amount (in parentheses) 
emissions because such boilers currently burn high-S fuel. If such a path were found to be optimal on other criteria, lower-S oil or desulfurization could be used. The hybrid options are less energy-intensive than all of the other pathways. The least total energy and oil use is by the current design HEV, with the PHEV in CS mode (extremely similar operation) very close behind. These two pathways have the least GHG and NOx emissions, and are generally comparable in other pathway emissions.

\subsubsection{Natural Gas Pathway Comparison}

Table 4 summarizes energy inputs and emissions for each of the pathways using natural gas as its feedstock. The most total energy and natural gas is used by the Fischer-Tropsch diesel pathway. This pathway also produces the most GHGs, twice as much as the lowest GHG option. The only other noteworthy emission is the CO from SI ICE combustion of CNG, which is an order of magnitude larger than from all the other natural gas pathways, but similar to SI ICE combustion of petrol. The lowest impacts by far are seen with the PHEV in all-electric CD mode, with the electricity produced in an efficient combined-cycle plant.

Some may find the size of the difference between the PHEV CD mode results and the GH2 FCV results to be large. We reiterate earlier discussion. First, note that, although the FCV is an HEV with a Li-ion battery pack, as is the case for the latest Honda fuel cell prototype [36], the simulated FCV does not operate in the same manner as the SI ICE HEV and PHEV. For the former, fuel flow is eliminated during decelerations and vehicle idle. This involves repeated engine shutdowns and restarts. Due to concerns over effects on early fuel cell reliability, we did not simulate repeated shut downs of the $2015 \mathrm{FCV}$ at vehicle stops, as is done in the HEV and PHEV, nor did we shut off hydrogen flow during decelerations. This significantly (but appropriately) penalizes the FCV in our simulations. Another decision

\begin{tabular}{|l|r|r|r|r|r|}
\hline $\begin{array}{c}\text { 1000s of } \\
\text { joules/km }\end{array}$ & CIDI GTL FTD & SI ICE CNG & $\begin{array}{c}\text { GH2 FCV HEV } \\
\text { Steam methane } \\
\text { reforming }\end{array}$ & $\begin{array}{c}\text { PHEV CD Sim- } \\
\text { ple Cycle }\end{array}$ & $\begin{array}{c}\text { PHEV CDCom- } \\
\text { bined Cycle }\end{array}$ \\
\hline Total Energy & 4,149 & 3,486 & 3,449 & 3,038 & 2,182 \\
\hline Petroleum & 132 & 130 & 162 & 2,823 & 109 \\
\hline Natural gas & 3,836 & 3,033 & 389 & 198 & 1,848 \\
\hline Coal & 159 & 274 & & 195 & 196 \\
\hline \multicolumn{1}{|c|}{ Grams/km } & & & 232 & 0.151 & 142 \\
\hline GHGs & 261 & 232 & 0.149 & 0.238 & 0.144 \\
\hline VOC & 0.192 & 0.224 & 0.201 & 0.229 \\
\hline CO & 0.531 & 2.358 & 0.235 & $0.219(0.103)$ & $0.120(0.024)$ \\
\hline NOx * & 0.246 & 0.242 & 0.056 & 0.035 & 0.034 \\
\hline PM2.5 & 0.057 & 0.17 & 0.271 & $0.212(0.000)$ & $0.203(0.000)$ \\
\hline SOx * & 0.153 & & & & \\
\hline
\end{tabular}

Table 4: Natural gas pathway energy use and emissions (1 battery replacement)

* According to ref. 21, when utility NOx or SOx emissions caps exist, GREET estimates of upstream emissions will in practice be reduced by the power plant amount (in parentheses)

(C) 2008 WEV Journal, pp. $x-x$ was to use GREET's “decentralized” steam methane reforming option, rather than the more efficient centralized option. The decentralized option for 2015 involves small scale reforming facilities, tapping into existing natural gas pipeline infrastructure.

Further, we do not include in our 2015 cases a PHEV FCV, though such a vehicle is certainly possible beyond 2015. We do note that the Honda fuel cell vehicle has switched from use of ultracapacitors for energy storage to a Li-ion battery [36]. We have done PHEV FCV simulations, which will be presented when a paper is done with a time frame beyond 2015. The unreported simulations do show significant gains relative to the case illustrated here, though certainly not enough to eliminate the existence of a significant advantage for a PHEV in CD mode using electricity from a combined cycle natural gas fueled power plant.

\subsubsection{Coal pathway comparison}

The total energy, coal use and GHG emissions from the CTL pathway are by far the largest of all of the pathways using coal to supply light-duty vehicle kilometers (Table 5), although SOx emissions are lowest. Although we did not include the CIDI HEV in the vehicle simulations for this study, a point of reference is the CIDI HEV prototype by Peugot [30], which was said to reduce fuel consumption by $28 \%$ in European certification tests. If this is a reasonable estimate, then the PHEV operating in CD mode would still use less coal per mile of service provided. However, production of petrol from coal (not considered for years; not included here) to service the PHEV in CS mode would use even more coal per $\mathrm{km}$ than CIDI CTL FTD [34].

All of the options use similar and small quantities of natural gas and petroleum, presumably contributed by the vehicle cycle. Among the three options that supply electricity to PHEVs, the lowest impacts come from the 


\begin{tabular}{|c|c|c|c|c|}
\hline $\begin{array}{c}1000 \mathrm{~s} \text { of } \\
\text { joules } / \mathrm{km}\end{array}$ & CIDI CTL FTD & $\begin{array}{l}\text { PHEV CD Cur- } \\
\text { rent Boiler }\end{array}$ & $\begin{array}{c}\text { PHEV CDNew } \\
\text { Boiler }\end{array}$ & $\begin{array}{c}\text { PHEV CDIG } \\
\text { Combined Cycle } \\
\text { (No CO2 } \\
\text { Capture) }\end{array}$ \\
\hline Total Energy & 4,726 & 2,829 & 2,591 & 2,194 \\
\hline Petroleum & 124 & 130 & 127 & 122 \\
\hline Natural gas & 162 & 204 & 203 & 203 \\
\hline Coal & 4,416 & 2,462 & 2,229 & 1,838 \\
\hline \multicolumn{5}{|l|}{ Grams/km } \\
\hline GHGs & 500 & 283 & 258 & 218 \\
\hline $\mathrm{VOC}$ & 0.195 & 0.147 & 0.145 & 0.143 \\
\hline $\mathrm{CO}$ & 0.482 & $\begin{array}{r}0.211 \\
\end{array}$ & $\begin{array}{r}0.211 \\
\end{array}$ & $\begin{array}{r}0.188 \\
\end{array}$ \\
\hline $\mathrm{NOx} *$ & 0.121 & $0.270(0.186)$ & $0.268(0.186)$ & $0.146(0.069)$ \\
\hline PM2.5 & 0.196 & $\begin{array}{r}0.124 \\
\end{array}$ & $\begin{array}{r}0.114 \\
\end{array}$ & $\begin{array}{r}0.096 \\
\end{array}$ \\
\hline $\mathrm{SOx} *$ & 0.118 & $0.687(0.486)$ & $0.686(0.486)$ & $0.266(0.069)$ \\
\hline
\end{tabular}

Table 5 Coal pathway energy use and emissions ( 1 battery replacement)

* According to ref. 21, when utility NOx or SOx emissions caps exist, GREET estimates of upstream emissions will in practice be reduced by the power plant amount (in parentheses)

efficient combined cycle plant. Unfortunately, within coal options, according to the recent evaluation in Duvall and Knipping [24], pulverized coal and supercritical pulverized coal technologies are more cost competitive than the integrated gasification and combined cycle (IGCC) coal power plant. Their analysis implied that only aggressive carbon standards or carbon taxes would be likely to cause the IGCC technology to begin to attain a significant share of new coal powerplant construction. Supercritical pulverized coal, which is a less efficient advanced technology than the IGCC technology, would be adopted with less aggressive carbon reduction incentives, but not at all absent carbon reduction incentives [24].

The long-term PHEV air quality study by Knipping and Duvall [23] projected significant numbers of new coal plants and installation of emissions control devices on both new and old plants, resulting in a system wide reduction of $\mathrm{NOx}$ and $\mathrm{SOx}$ emissions per $\mathrm{kWh}$ sold to PHEVs, due to regulatory caps on NOx and SOx emissions from power plants. Thus, the "new boiler" case is the most relevant for this study, with an assumption that emission control regulations force GREET's estimated power plant SOx and NOx emissions to be eliminated.

\subsubsection{Farmed trees and wind/solar pathway comparison}

For farmed trees (Table 6), as for the other feedstocks, the option that supplies liquid fuel for direct use in a conventional vehicle uses the most total energy and the most feedstock. However, that option also minimizes SOx emissions. The conventional SI HEV FFV using $85 \%$ ethanol fuel uses considerably less energy than the base SI ICE FFV, but not as little as the PHEVs in allelectric CD mode. As in all cases above, the farmed trees

\begin{tabular}{|c|c|c|c|c|c|c|c|}
\hline & \multicolumn{5}{|c|}{ Farmed Trees } & \multicolumn{2}{|c|}{ Wind/Solar } \\
\hline $\begin{array}{c}\text { 1000s of } \\
\text { Joules/km }\end{array}$ & $\begin{array}{l}\text { SI ICE } \\
\text { FFVE85 }\end{array}$ & $\begin{array}{c}\text { PHEV } \\
\text { CS }\end{array}$ & $\mid \begin{array}{c}\text { SI HEV FFV } \\
\text { E85 Ni-MH } \\
\text { Battery }\end{array}$ & $\begin{array}{c}\text { PHEV } \\
\text { CD } \\
\text { Boiler }\end{array}$ & $\begin{array}{c}\text { PHEV } \\
\text { CD } \\
\text { Combined } \\
\text { Cycle }\end{array}$ & $\begin{array}{c}\text { Electrolysis } \\
\text { GH2 } \\
\text { FCV } \\
\text { HEV }\end{array}$ & $\begin{array}{c}\text { PHEV } \\
\text { CD }\end{array}$ \\
\hline Total Energy & 5,336 & 3,884 & 3,660 & 3,000 & 2,372 & 3,059 & 1,292 \\
\hline Petroleum & 928 & 557 & 522 & 159 & 144 & 152 & 99 \\
\hline Natural gas & 171 & 203 & 182 & 209 & 206 & 319 & 199 \\
\hline Coal & 52 & 120 & 108 & 198 & 197 & 398 & 193 \\
\hline Grams/km & & & & & & & \\
\hline GHGs & 68 & 56 & 51 & 40 & 40 & 75 & 40 \\
\hline $\mathrm{VOC}$ & 0.307 & 0.252 & 0.248 & 0.144 & 0.133 & 0.131 & 0.129 \\
\hline $\mathrm{CO}$ & 2.479 & 2.452 & 2.446 & 0.352 & 0.193 & 0.156 & 0.165 \\
\hline $\mathrm{NOx}$ * & 0.373 & 0.291 & 0.276 & $0.336(0.25)$ & $0.096(0.02)$ & 0.109 & $0.058(0.00)$ \\
\hline PM2.5 & 0.041 & 0.04 & 0.038 & 0.041 & 0.032 & 0.037 & 0.025 \\
\hline $\mathrm{SOx} *$ & 0.084 & 0.183 & 0.159 & $0.259(0.07)$ & $0.258(0.07)$ & 0.235 & $0.186(0.00)$ \\
\hline
\end{tabular}

Table 6: Renewable pathways energy use and emissions (1 battery replacement)

* According to ref. 21, when utility NOx or SOx emissions caps exist, GREET estimates of upstream emissions will in practice be reduced by the power plant amount (in parentheses) 


\begin{tabular}{|c|c|c|c|c|c|}
\hline Battery Type & $\mathrm{Ni}-\mathrm{MH}$ & Li-Ion & Li-Ion & Li-Ion & Li-Ion \\
\hline Vehicle Type & HEV & PHEV16 & PHEV32 & PHEV64 & FCV \\
\hline Weight (kg) & 43.9 & 49.6 & 76.4 & 130.7 & 41.9 \\
\hline \multicolumn{6}{|l|}{$\begin{array}{c}1000 \mathrm{~s} \text { of } \\
\text { Joules } / \mathrm{km}^{*}\end{array}$} \\
\hline Total Energy & 44.5 & 48.5 & 68.8 & 109.7 & 46.3 \\
\hline Coal & 25.6 & 23.8 & 33 & 51.4 & 13.9 \\
\hline Natural gas & 10.4 & 13.8 & 20.1 & 32.7 & 13.3 \\
\hline Petroleum & 3.6 & 6.1 & 9.2 & 15.3 & 5.8 \\
\hline GHGs $(\mathrm{g} / \mathrm{km})$ & 3.55 & 3.84 & 5.44 & 8.67 & 3.67 \\
\hline \multicolumn{6}{|l|}{ Gram/1000km } \\
\hline VOC & 0.34 & 0.35 & 0.49 & 0.78 & 0.34 \\
\hline $\mathrm{CO}$ & 2.53 & 1.09 & 1.55 & 2.47 & 1.04 \\
\hline $\mathrm{NOx}$ & 3.9 & 4.43 & 6.3 & 10.07 & 4.23 \\
\hline PM2.5 & 1.31 & 1.48 & 2.08 & 3.3 & 1.8 \\
\hline $\mathrm{SOx}$ & 28.22 & 26.77 & 39.73 & 65.8 & 21.92 \\
\hline
\end{tabular}

Table 7: Battery production energy use and emissions - o replacements

* We divide by the annual kilometers of use of the vehicle. It may be more reasonable to divide by the estimated kilometers of CD mode operation.

option using combined cycle power production looks most promising on the basis of total energy, and in this case all impacts. The finding that more kilometers of service from the chosen biomass feedstock resource base would be obtained by burning the trees in a power plant than converting them to ethanol is directionally consistent with a similar assertion made recently by Eberhard [37].

For options relying on wind or solar energy, the PHEV in CD mode again consumes the lowest energy per mile, less than half that of the GH2 FCV option, and also reduces all but $\mathrm{CO}$ emissions.

\subsection{Battery Production Energy Use and Emissions}

We have provided full fuel cycle plus vehicle cycle energy and emissions estimates as if the battery were replaced once during the vehicle's life. For those interested in doing some sensitivity analysis computations concerning our current estimates of the energy and emissions impacts of the batteries, we provide this separate table (Table 7) of the energy use and emissions due to the battery packs alone, for one battery serving the entire vehicle life. The rate is in terms of $\mathrm{km}$ of vehicle life. Our present estimates assume limited recycling, and are based on one battery chemistry. There are multiple promising Li-ion battery chemistries under consideration for PHEVs [27]. Recycling remains to be investigated in detail. Recognizing that we provide first rough estimates for energy and emissions effects of battery packs, it appears that the battery pack impacts will not deter implementation of PHEVs. The share of total pathway emissions caused by batteries is not negligible - a few percent at most, but in the reference PHEV considered, it brings indirect fuel cycle pathway energy, fuel use, and emissions reduction benefits that swamp the vehicle cycle emissions increases that it causes. In
Table 7, in addition to the reference PHEV32 used in this study, we provide battery mass, energy and emissions values for a simulated PHEV16 and PHEV64. This covers the span of CD all electric range values presently being considered by General Motors - the Volt is said to be designed for $64 \mathrm{~km}$ of AER, while the Saturn Vue is to be designed for $16 \mathrm{~km}$ of AER [38]. The differences in CD and

CS fuel use for the three PHEV range cases are small enough that a presentation of results for one, as we have done here, is sufficient for the pathway comparisons we present.

\subsection{Most Favorable Pathways Overall}

\subsubsection{Energy and scarce fossil resources}

In Figure 2 we present the total energy consumption for the pathways we investigated. For each of the four feedstocks, we order the cases from most energy intensive per kilometer of operation to least intensive. At the end of that ordering of alternatives, for all but the oil feedstock case we find that charge depleting operation of a PHEV uses the least feedstock. In every case where a combined cycle powerplant is included, that case, serving charge depleting operation of a PHEV, uses the least energy. What we see is that the HEV and PHEV powertrains, and combined cycle power generation technology appear to be a very advantageous combination. We cannot not "go wrong," regardless of non-oil feedstock, by emphasizing PHEV and combined cycle technologies as a means of both reducing oil use per kilometer of service in CD mode and as a means of efficiently switching from away from oil to other feedstocks.

The final bar in Fig. 2 provides an annual average estimate for full year operation of a PHEV operating on petrol from crude oil in CS mode, and wind/solar energy 


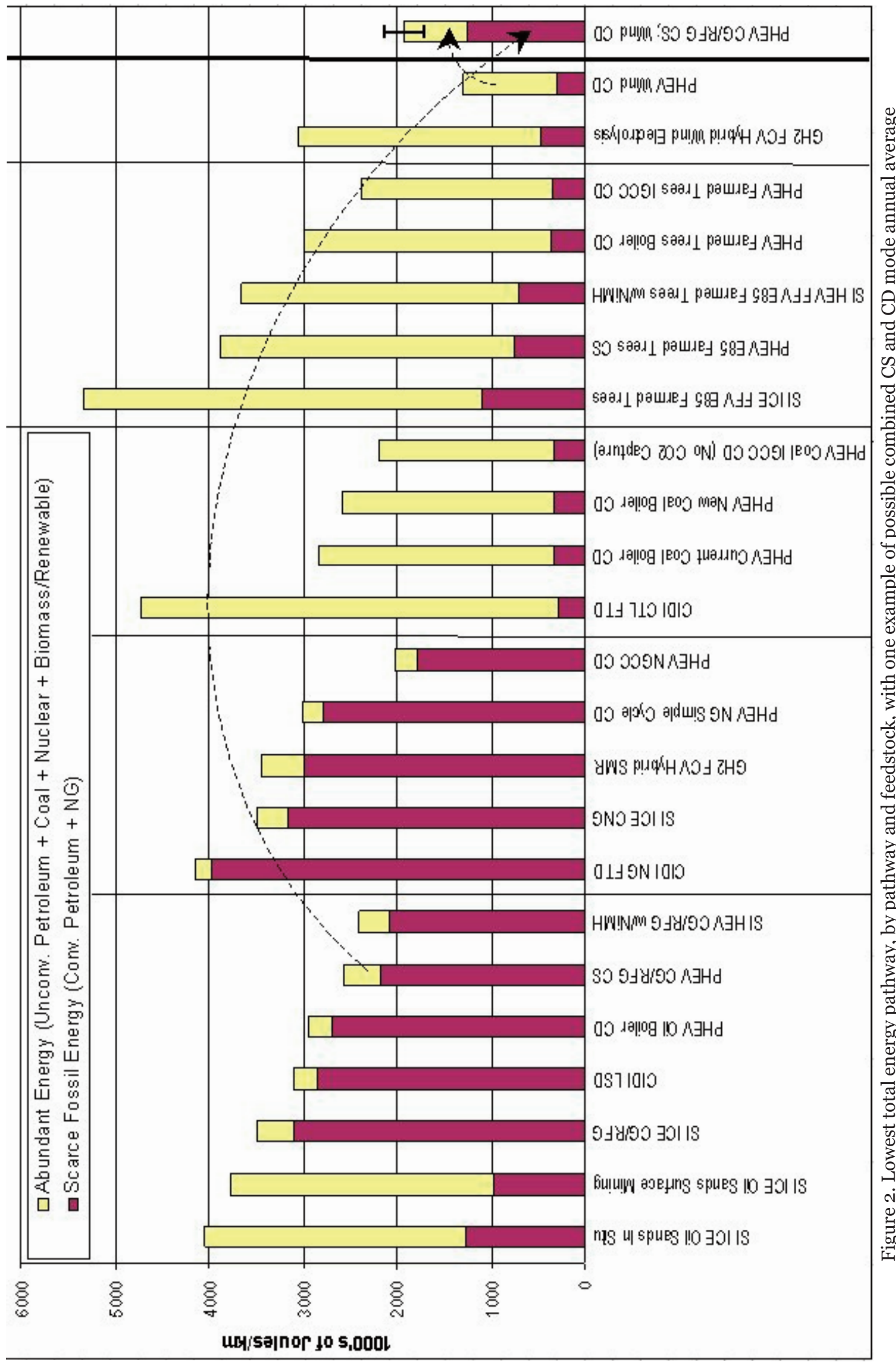

CC 2008 WEV Journal, pp. $x-x$ 
in CD mode (the best CD option). The reference case for the bar assumes that $50 \%$ of kilometers of service are provided by CD operation. The worst case assumes $33 \%$, and the best case $67 \%$. The worst case is represented by the SAE's recommended "utility factor" method, for a PHEV with $32 \mathrm{~km}$ of all electric range [10]. The best case would most likely require charging at more locations than just the home garage, and very careful driving by the vehicle owner, with modest accelerations. The average daily per vehicle driving distance in the U.S. is approximately $60 \mathrm{~km} \mathrm{[25],} \mathrm{so} \mathrm{a}$ PHEV with $32 \mathrm{~km}$ range would have to be recharged well beyond once per day to achieve a $2 / 3$ reduction of petrol use. However, it is plausible that it could be done. In addition to the plotting of total energy, we also plot "scarce fossil energy" - the sum of conventional petroleum and natural gas energy. Canadian oil sands are not regarded as scarce. From this perspective, coal and farmed trees look very good, as does wind.

\subsubsection{Greenhouse gases}

The results for GHGs are heavily dependent on the WTP pathway chosen. The general finding that renewables reduce GHGs is well documented and is found in other studies as well. However, the fact that we separately present per kilometer estimates for the charge depleting mode causes some interesting observations. Regardless of pathway, when one switches to a feedstock other than conventional oil, the best option for that other feedstock is a PHEV operating in CD rather than CS mode. This argues for finding ways to increase the actual use of CD operation, for the PHEV type characterized for this paper, should it be one to succeed in the marketplace. Within the two renewables categories we have investigated (farmed trees and wind/solar), our estimates imply that use of those renewables to create electricity to provide kilometers of service in charge depleting mode results in the lowest GHG emissions, among the cases compared. We find the same result within the natural gas pathway, and in the coal pathway, even were we to consider that diesel hybrids using CTL might eventually be introduced. Obviously to obtain the significant GHG benefits obtainable in CD mode operation, one needs the PHEV powertrain. The comparisons do include both CIDI and FCV options.

For charge sustaining operation of the SI ICE PHEV we have characterized, neither coal nor natural gas provides an option as attractive in GHG emissions rate as using petrol produced from conventional oil in an HEV. A PHEV FFV in CS mode could use E85 from farmed trees, at only a $5 \mathrm{~g} / \mathrm{km}$ penalty relative to an FFV HEV. On an annual average basis, if PHEV FFVs existed, using CD mode for $50 \%$ of driving and depending only on farmed trees for feedstock for E85 and electric power, they would emit slightly less GHGs than FFV HEVs, but could obtain considerably more annual kilometers of service from a given amount of farmed tree feedstock (in the event that combined cycle power plants succeeded). Of course discussion of this hypothetical case is inconsistent with our recognition that only minor changes among available feedstocks can occur between now and 2015 .

By Duvall and Knipping's estimates, PHEVs served by coal generators have about the same GHGs as does a HEV on petrol. This is also true for Shelby and Mui [20] and for Kromer and Heywood [21]. In our case, we estimate that the HEV on petrol has lower GHGs. The reason this is true, is that we have simulated HEVs that are more effective in reducing petrol use than did other authors. This may be due to our assumption of a Priuslike body rather than a standard U.S. sedan, a question we will examine in the future. In the 2001 EPRI study, the simulated vehicle similar to a Prius had a considerably greater percentage reduction in estimated fuel consumption when hybridized, than did the study's focus - an average mid-size car [10].

Other analysts commonly choose to compare PHEV emissions to full HEV (such as the split hybrid) emissions. However, we caution readers to be careful not to lose sight of the fact that PHEVs using coal in new boilers for CD mode operation are here estimated to have lower GHG emissions than conventional vehicles using petrol from oil sands. If PHEVs are sold when an $\mathrm{HEV}$ would not be sold, even if they use coal for electric power, those particular PHEVs would not have a tendency to increase GHG emissions. Further, in CS mode they would do considerably better than the conventional vehicle they replaced. Our results certainly do imply that if a split hybrid powertrain PHEV replaces a split hybrid powertrain HEV and uses coal for CD mode operation, it will cause an increase of GHG emissions. An observation that we make in a companion EVS paper [25] is that there will likely be a positive synergism between "full" $\mathrm{HEV}$ powertrains (such as split hybrids) and PHEVs. Full HEVs are ones capable of some degree of all electric operation. In terms of reduction of fuel consumption, they are more effective than other HEV powertrain types, including mild hybrids and integrated starter generator hybrids [39]. Thus, we note that if the PHEV option causes the odds of purchase of a full HEV powertrain instead of a conventional vehicle (or mild HEV powertrain) to rise (one of the arguments in our companion paper), the proper comparison of the PHEV would often be to less efficient mild $\mathrm{HEV}$ or the even less efficient conventional powertrain, not the full HEV. In reality, some PHEVs will compete away full HEVs, some will compete away mild HEVs, and others will compete away conventional vehicles. Duvall and Knipping [24] assumed an even split between the HEV and conventional categories of vehicle replacement in their analysis, but did not consider competition with mild hybrids.

These complicated comparisons having been discussed, 
we nevertheless concede that, if GHG emissions are a priority, it would be desirable that relatively inefficient coal fired power plants provide only a small portion of the power for PHEV CD mode operation.

Those interested in GHG results will undoubtedly want to construct their own estimate concerning expectations of reduction or increase. Recall in section 5.1.1 that we assumed a mix of power generation sources as of 2015. Vyas et al. [25] predict that PHEVs will expand the total market for HEV powertrains, in many cases being chosen instead of a conventional petrol or diesel option. The most recent analysis by staff of the Massachusetts Institute of Technology Laboratory for Energy and the Environment [21], when compared to earlier market share scenarios and technology pathways, expands the total share of petrol HEVs by adding PHEVs [40, 41]. For the two studies of national PHEV market effects that provided time paths of change in total GHG emissions along with simulation of shifts in shares of electric generators, by technology and fuel type, total GHG emissions in 2015 were reduced in both cases [16, 20, 42].

For the period to 2015, the results here and investigation of other studies suggest that efforts to introduce PHEVs for purposes of energy conservation and energy security can be done with little concern that GHGs will increase in the process. It appears far more likely that GHGs will decrease slightly at worst, and could decrease significantly if policies to encourage use of combined cycle natural gas power plants, farmed trees, and wind were adopted.

\subsubsection{Criteria pollutants (VOC, CO, NOx, PM2.5, SOx)}

\subsubsection{Discussion of criteria pollutant results}

The Knipping and Duvall study [23] addresses two major remaining U.S. air quality problems - ozone and particulate matter. Among the criteria pollutants that we have reported on, $\mathrm{VOC}, \mathrm{CO}$, and $\mathrm{NOx}$ are ozone precursors (they mix in the atmosphere and on hot and sunny days chemical reactions lead to ozone pollution). For particulates, we include direct emissions of particulate matter (PM2.5), and three pollutants that can lead to secondary particulate formation in the atmosphere (VOC, NOx and SOx).

Our estimates imply that a switch from a conventional petrol vehicle to a PHEV operating in CDE mode (all electrically) will consistently reduce ozone precursors, if a NOx cap is in place (net powerplant NOx emissions changes are zero). This is consistent with the results in the Knipping and Duvall study for the year 2030, where it was found that ozone was reduced in most regions.

For particulates, our estimates imply that the best natural gas and renewables pathways would reduce both NOx and PM2.5, relative to either a conventional petrol or hybrid vehicle. Our results do imply that total pathway SOx emissions would go up. The reader is reminded that these results are preliminary, and that only partial recycling is assumed. Thus, these results are a signal that this is one area to evaluate in more detail in the future.

The reader is also reminded that we have not separated out urban from upstream emissions. The CD mode of operation displaces emissions from urban areas to more remote locations. When total pathway emissions differences are positive but not large, this displacement of emissions could actually result in significant reductions of population exposure. This point is also valid for vehicle cycle pathway emissions, early stages of which (mining) not only occur outside of most metropolitan regions, they also often occur outside the United States. Vehicle cycle emissions occur at a different time and place than tailpipe emissions, as do electric generation emissions associated with the PHEVs. Interpretation of criteria pollutant results is therefore complex and challenging.

The discussion to this point involved an assumption of all electric operation during CD. However, for criteria pollutants we cannot assert that our results are entirely valid for the 2015 time frame, and not just because we have not presented GREET's traditional separate urban and upstream emissions estimates. In the previously mentioned companion paper [25], we present arguments that the most economic near-term implementation of PHEVs would use a "blended mode" of operation, in which the engine would come on intermittently as the battery depleted. In this analysis, like all other cited analyses that have evaluated PHEVs, the assumption has been that the PHEVs will operate all electrically as the battery charge depletes. If the blended mode of operation is to be implemented, additional studies will be needed to evaluate the criteria pollutant emissions. If the blended mode option is not implemented - in the near term at least - the battery costs per PHEV will be pushed up [25] and the market share of PHEVs will likely be much more limited and thus the nation's net energy, oil and GHG reductions less. Our evaluations do imply that conclusions about energy, oil and GHGs will be robust, whether a (well conceived) blended or allelectric CD mode is implemented.

We have tried to point out that the way that PHEVs will be purchased and used in the marketplace involves complex trade-offs that future customers will make. Simple pairwise comparisons, which tend to be encouraged by the enlightening, but conceptually constraining LCA approach, are not sufficient.

The HEVs and PHEVs that have been characterized in this paper are very efficient. If an average U.S. consumer owned these vehicles and drove in the same manner as in a conventional vehicle, then the vehicle's 
engine would come on intermittently during CD. The emissions effects of such a pattern of driving in mass market PHEVs remain to be determined. However, it should also be noted that the vehicles characterized here could in many circumstances be driven all electrically, if the owners of the vehicles chose to accelerate gently and choose routes other than high speed limited access motorways. Though the information was limited, EPA observed that HEVs in Kansas City were driven more gently than conventional petrol vehicles [45]. It may also prove to be the case that a well educated purchaser of an early PHEV will understand that the petrol savings achieved with such vehicles will be considerably more sensitive to driving behavior than for a conventional vehicle. One may expect earlier purchasers to be particularly interested in achieving the maximum petrol reduction possible from their PHEV investment. In attempting to achieve this result, the drivers would increase the odds of driving all electrically.

We also note that the vast majority of the U.S. population lives in areas where air quality standards are met. So long as the maintenance of air quality standards can continue, we see no reason within the results presented to cause us to suggest that the nation forego the near term energy, oil, and GHG reduction opportunities provided by early PHEVs. However, it does seem clear to us that the understanding and assessment of criteria pollutant emissions may require additional attention in the future, particularly if the costs of assuring all electric mode operation remain daunting.

The total energy cycle tool is useful to a point particularly for energy, oil and GHG investigation. However, the understanding and evaluation of criteria pollutant effects, both positive and negative, requires far more information than GREET can provide. Highly sophisticated and costly analyses such as the recent national EPRI and NRDC investigation of the effect of advanced long-term PHEVs on air quality [24] are necessary to help us learn about the air quality and public health effects of introducing PHEVs of different levels of electric operations capability. In addition to such national and regional air quality studies, once additional data on attributes of early mass market PHEVs becomes available, "micro-scale" modeling at the intersection and network level may also be valuable.

\subsubsection{Criteria pollutant research needs for degrees of PHEV blended mode capability}

One issue that needs careful attention involves the degree of ability to eliminate cold and warm engine starts as a function of degree of CD capability of batteries and motors. Cold starts cause far greater criteria pollutant emissions penalties than fuel consumption penalties. As a result of the study of real world driving in Europe, Andre estimated that fully 70\% of all cold starts occur in "urban" driving, which was estimated to constitute $27.9 \%$ of kilometers traveled, at an average speed of only $22.5 \mathrm{~km} / \mathrm{h}$, and average length of $3.4 \mathrm{~km}$ [43]. These slow trips represented half of the time spent in travel. Such short, low speed trips might be successfully operated all electrically in a PHEV that would officially be a "blended" mode PHEV by California Air Resources Board certification procedures [44]. Andre noted that a significant portion of urban driving is also an integral part of longer trips, occurring at the beginning and end of each trip. Perhaps an electrically heated catalyst in a PHEV (as assumed in Vyas et al. [25]) could warm up within the time frame and distance represented by the initial low speed "urban" segment of the trip, followed by a relatively low emissions warm start. Note that the urban segments could also be thought of as neighborhood driving, where hard sustained accelerations that could cause a need for engine assist would be illegal. The top speed of European urban trips was under $60 \mathrm{~km} / \mathrm{h}$ [43]. This is clearly an area worthy of additional study.

Another area that requires attention, which could have favorable implications for PHEVs, is the particulate reducing brake wear benefit of regenerative braking, with attention to detail concerning what happens at intersections and crossroads, where pedestrians wait at corners to cross. For urban driving, Andre estimated 1.8 stops per $\mathrm{km}$, in contrast to 0.4 for rural/suburban, and 0.1 for motorway travel. PHEVs may seldom operate with the engine on near busy intersections in slow stop and go driving in the vicinity of sidewalks. In terms of health and exposure benefits, this could potentially be a very pronounced benefit. It may be available and valuable even in blended mode. Europe is more interested in designing vehicles to be electric drive capable just in the crowded high pedestrian use areas of cities than the U.S. has been. This may be a lesser challenge, with a very large benefit.

\section{DISCUSSION}

This paper has focused on developing an understanding of what could be accomplished in the near term ( to $\sim 2015$ ) by a hypothetical, highly efficient PHEV, based on the current top selling powertrain architecture, the split hybrid. The case examined is one where the split hybrid HEV and PHEV designs are devoted to enhancing fuel efficiency while maintaining functionality for a passenger car suitable for urban use worldwide. However, the evaluation focuses on the assumed production and use of such a vehicle in the United States. Unlike other studies, which generally estimate an annualized change in fuel use and emissions for vehicles compared, this study has focused on an incremental investigation of what is accomplished by offering a PHEV option as an addition to an HEV. The ability to operate in charge depletion mode, using grid electricity, is what is purchased when the PHEV is chosen. Therefore, we have separated out the effects of 
CD operation in this study. This allows us to think in terms of the potential per kilometer effects of choosing batteries for PHEVs, in lieu of continued use of conventional petrol or natural-gas-fueled powertrains, petrol HEVs, E85 FFVs, or future use of E85 FFV $\mathrm{HEVs}$, emerging clean diesel (CIDI) engines or fuel cell (FC) powertrains.

Due to an anticipated mix of natural gas and coal fired power, leavened with a small amount of wind power, PHEVs, operating in charge depleting mode will very sharply reduce oil use per kilometer and also very consistently reduce GHGs, in some cases by large amounts.

Direct effects on air quality cannot be determined until specific PHEVs emerge and are emissions tested. The vehicles simulated here have some all electric capability in CD mode. However, the extent to which first generation PHEVs will result in all-electric vs. blended operation, and the nature of emissions during blended operation are clearly to be determined. To the degree that the PHEVs simulated here were driven all electrically, the results imply that such driving would reduce ozone precursors. Overall effects on ambient concentrations of particulate matter seem uncertain. Nevertheless, since the likely differences in total emissions per kilometer do not appear to be large, the "displacement" effect (removal of emissions in the proximity of roadways to much more remote power plants) seems likely to reduce public exposure to particulate matter. In any case, as the Knipping and Duvall study [23] found, the (beneficial) effects of PHEVs when operating all electrically are relatively small compared to all sources of pollution. In our opinion, the estimates presented imply that there are no criteria pollutant effects that cannot be successfully addressed. More optimistically, realization of some valuable air quality and human exposure benefits via evolution of the design and use strategies for the technology seems attainable.

We examined the relative contribution of battery assembly and disposal on total pathway emissions of HEVs and PHEVs. We estimated the effects to be small, even if the battery had to be replaced once in the vehicle's lifetime.

Should a goal be to obtain the most kilometers of service per unit of feedstock, this study found that the use of combined cycle power generation technology providing electricity for PHEV charge depletion was the best option, in every case where such a generation technology was considered.

With regard to the desire to use relatively abundant and/or sustainable domestic fuels, coal, farmed trees, and wind/solar are each enabled by PHEVs. If coal is to be used to create kilometers of service, our estimates imply that more kilometers of service will be obtained by use of CD mode in PHEVs than by use of CTL in CIDI engines. For farmed trees it was estimated that use of CD mode in PHEVs would be provide more kilometers of service per unit of feedstock than would conversion of trees to ethanol for use in $\mathrm{HEV}$ s or in PHEVs in charge sustaining mode. In the case of wind/solar, due to the energy intensive nature of electrolysis, it was also estimated that use of CD mode in PHEVs would provide far more kilometers of service than creation of hydrogen for FCVs. Thus, regardless of which abundant domestic fuel one would wish to use, use of the fuel to serve a PHEV in CD mode would provide more kilometers of service than competing options evaluated.

While we have here highlighted and isolated the effects of $\mathrm{CD}$ operation of a PHEV, we recognize that evaluations of the aggregate annual impacts, including CS operation, should be considered. Future research will endeavor to explore CD, CS, and annual average operations separately and jointly, and in more detail than discussed here.

Finally, we concede that this study is limited, in terms of $\mathrm{HEV}$ and PHEV powertrain types investigated, and in the time interval considered. It also largely ignores the potential implications of regulations or taxes on carbon emissions. Nevertheless, it verifies the promise of PHEVs in the near-term, helping assure that research and development dedicated to the introduction and implementation of this technology is well founded.

\section{ACKNOWLEDGMENTS}

The authors of this paper would like to gratefully acknowledge the sponsorship of Ed Wall, Program Manager and Tien Duong, Team Leader, Hybrid and Electric Systems, Office of Vehicle Technologies, U.S, Department of Energy.

The submitted manuscript has been created by UChicago
Argonne, LLC, Operator of Argonne National Laboratory
("Argonne"). Argonne, a U.S. Department of Energy Office
of Science laboratory, is operated under Contract No. DE-
AC02-06CH11357. . The U.S. Government retains for itself,
and others acting on its behalf, a paid-up nonexclusive,
irrevocable worldwide license in said article to reproduce,
prepare derivative works, distribute copies to the public,
and perform publicly and display publicly, by or on behalf
of the Government.

\section{REFERENCES}

1. Ng, H.K., J.L. Anderson, and D.J. Santini, Electric and Hybrid Vehicles: a 25-Year Forecast, Automotive Engineering, 104( 2):66-70 (February 1996).

2. Singh, M. and D. Santini, Moving towards a userfriendly EV total energy cycle model, presented at TRB Workshop on Air Quality Impacts of Conventional and Alternative Fuel Vehicles, Ann Arbor, MI (Aug 3, 1998). 3. Singh, M.K., Total Energy Cycle Energy Use and 
Emissions of Electric Vehicles, Transportation Research Record 1664. Paper no. 99-0559, pp. 90-99 (1999).

4. Stodolsky, F., et al., Total Fuel Cycle Impacts of Advanced Vehicles. SAE technical paper 1999-01-0322, Society of Automotive Engineers, Warrendale, PA (1999).

5. Weiss, M.A., et al., On the Road in 2020: A LifeCycle Analysis of New Automobile Technologies, MIT Energy Laboratory Report \# MIT EL 00-003, Energy Laboratory, Massachusetts Institute of Technology, Cambridge, Mass., (Oct. 2000).

6. Weiss, M., et al., Comparative Assessment of Fuel Cell Cars, Massachusetts Institute of Technology, Laboratory for Energy and the Environment Report No. MIT LFEE 2003-001 RP, Cambridge, MA (2003).

7. Heywood, J., Opportunities for Reducing Oil Demand of the U.S. Light-Duty Vehicle Fleet. Presented at LERDWG Meeting, Washington D.C. (Feb. 8, 2006).

8. General Motors Corp., et al., Well-to-Wheel Energy Use and Greenhouse Gas Emissions of Advanced Fuel/Vehicle Systems: North American Analysis Executive Summary Report. (Available electronically at Argonne National Laboratory's Transportation Technology Research and Development Center web site, www.transportation.anl.gov/. (2001).

9. Brinkman, N., et al., Well-to-Wheels Analysis of Advanced Fuel/Vehicle Systems - A North American Study of Energy Use, Greenhouse Gas Emissions, and Criteria Pollutant Emissions, Available at http://www.transportation.anl.gov/pdfs/TA/339.pdf (2005).

10. Graham, R., et al., Comparing the Benefits and Impacts of Hybrid Electric Vehicle Options, Final Report, EPRI 1000349, Electric Power Research Institute, Palo Alto, Calif. (July 2001).

11. Plotkin, S., et al., Hybrid Vehicle Technology Assessment: Methodology, Analytical Issues, and Interim Results, Argonne National Laboratory Report ANL/ESD-02-1, Argonne, IL. (Oct. 2001).

12. Vyas, A., H.K. Ng, D.J. Santini, and J.L. Anderson, Electric and Hybrid Electric Vehicles: A Technology Assessment Based on a Two-Stage Delphi Study, Argonne National Laboratory Report ANL/ESD-36 (Dec. 1997).

13. Gaines, L. and R. Cuenca, Costs of Lithium Ion Batteries for Vehicles, Argonne National Laboratory Report ANL/ESD-42. Argonne, IL (May, 1999).

14. Santini, D.J., Two Industry Developments That Justify Optimism About Potential for PHEV Success: (Powertrains and Batteries, Presented at the Electric Drive Transportation Association Conference and Exposition Washington DC. (Nov. 28-30, 2006).

15. Duong, T. Battery Requirements and Solutions for Plug-in Hybrids, Presentation at the Advanced Automotive Battery \& Ultracapacitor Conference, Long Beach, CA May 16-18.

16. Balash, P., Alternate pathways to reduced petroleum consumption and greenhouse gas emissions, Presented at the USAEE/IAEE North American
Conference, Denver CO. (Sept. 20, 2005).

17. Short, W. and P. Denholm. A Preliminary Assessment of Plug-In Hybrid Electric Vehicles on Wind Energy Market, National Renewable Energy Laboratory Report NREL/TP-620-39729. National Renewable Energy Laboratory, Golden CO (April, 2006). 18. Hadley, S.W. Impact of Plug-in Hybrid Electric Vehicles on the Electric Grid. Oak Ridge National Laboratory Report ORNL-TM/2006/554, Oak Ridge, TN (October, 2006).

19. Kintner-Meyer, M., K. Schneider, and R. Pratt. Impacts Assessment of Plug-in Hybrid Vehicles on Electric Utilities and Regional U.S. Power Grids Part1: Technical Analysi,. Pacific Northwest National Laboratory (2006).

20. Shelby, M. and S. Mui., Plug-in Hybrids, A Scenario Analysis. Presented at the 86th Annual Meeting of the Transportation Research Board, Washington, DC (Jan. 22, 2007).

21. Kromer, M. A. and J. B. Heywood, Electric Powertrains: Opportunities and Challenges in the U.S. Light-Duty Vehicle Fleet, Laboratory for energy and the environment publication No. LFEE 2007-03 RP. Massachusetts Institute of Technology, Cambridge MA. (May, 2007)

22. Clement-Nyns, K., K. Van Reusel, , and J. Driesen, The Consumption of Electrical Energy of Plug-in Hybrid Electric Vehicles in Belgium, EET-2007 European EleDrive Conference, Brussels, Belgium (May 30-June 1, 2007).

23. Knipping. E. and M. Duvall, Environmental Assessment of Plug-in Hybrid Electric Vehicles, Vol. 2 United States Air Quality Analysis Based on AEO-2006 Assumptions to 2030, Electric Power Research Institute Final Report 1015326, Electric Power Research Institute, Palo Alto CA (June, 2007)

24. Duvall, M. and E. Knipping, Environmental Assessment of Plug-in Hybrid Electric Vehicles, Vol. 1 Nationwide Greenhouse Gas Emissions, Electric Power Research Institute Final Report 1015325, Electric Power Research Institute, Palo Alto CA (July, 2007)

25. Vyas, A. et al., Plug-In Hybrid Electric Vehicles: How Does One Determine Their Potential for Reducing U.S. Oil Dependence? Electric Vehicle Symposium No. 23, Anaheim, CA (Dec. 2-5, 2007).

26. Burnham, A., M. Wang, and Y. Wu, Development and Applications of GREET 2.7 - The Transportation Vehicle Cycle Model, Argonne National Laboratory Report ANL/ESD/06-5. Argonne, IL (Nov. 2006)

27. Howell, D., Electrical Energy Storage. Plug-in Hybrid Electric Vehicle Battery Research and Development Activities, Presented at the U.S. Department of Energy PHEV Stakeholder Workshop, Washington DC (June 13, 2007).

28. U.S. Department of Energy, Energy Information Agency, Monthly Energy Review, Energy Information Administration, Washington, DC (July, 2007).

29. Argonne National Laboratory, PSAT (Powertrain Systems Analysis Toolkit), http://www.transportation.anl.gov/software/PSAT/ 
(2007).

30. Birch, S., Safety, style, the diesel hybrid - and the President, Automotive Engineering, SAE International. (July, 2006) pp. 124-125.

31. Freese, C. General Motors' Perspective on Diesel Markets. Diesel Engine-Efficiency and Emissions Research Conference, Detroit, MI (Aug. 12-16, 2007).

32. U.S. Environmental Protection Agency, Emissions \& Generation Resource Integrated Database (EGRID), http://www.epa.gov/cleanenergy/egrid/index.htm. (2004).

33. Larsen et al., Might Canadian Oil Sands Promote Hydrogen Production for Transportation? Greenhouse Gas Emissions Implications of Oil Sands Recovery and Upgrading. World Resources Review. V. 17 (2). pp. 220242. (2005).

34. International Energy Agency. Alcohols and alcohol blends as motor fuels. Swedish National Board for Technical Development, Information No. 580-1986. Stockholm. (Oct. 1986).

35. 109th Congress of the United States. Energy Policy Act of 2005. U.S. Congress, Washington, DC (2005).

36. Yamaguchi, J. Honda builds a better FCX. Automotive Engineering, SAE International. (July, 2007) pp. 54-57.

37. Eberhard, M., Tesla Motors. Presented at the California Air Resources Board ZEV Symposium, Sacramento, CA (Sept. 26, 2006).

38. Brooke, L., Hot off the Grid. Automotive Engineering, April 2007, pp 52-56.

39. Smokers et al. Review and analysis of the reduction potential and costs of technological and other measures to reduce $\mathrm{CO} 2$-emissions from passenger cars. Final Report. TNO Science and Industry Automotive business unit, Delft, Netherlands (Oct. 31, 2006).

40. Weiss, M., et al., Comparative Assessment of Fuel Cell Cars, Massachusetts Institute of Technology, Laboratory for Energy and the Environment Report No. MIT LFEE 2003-001 RP, Cambridge, MA. (2003).

41. Heywood, et al., The Performance of Future ICE and Fuel Cell Powered Vehicles and Their Potential Fleet Impact, Massachusetts Institute of Technology, Laboratory for Energy and the Environment Report No. MIT LFEE 2003-004 RP (Dec. 2003)

42. Santini, D.J., Broad Overview of Plug-in Hybrids and Analytical Studies, presented at the U.S. Department of Energy Plug-in Hybrid Vehicle Discussion Meeting, U.S. Department of Energy, Washington, D.C. (May 4-5, 2006). http://www.sentech.org/PHEV/Opening_Presentations/ Santini-

Broad\%20Overview\%20of\%20PHEVs\%20and\%20Analy tical\%20Studies.pdf

43. Andre, M., The ARTEMIS European driving cycles for measuring car pollutant emissions. Science of the Total Environment 334-335 (2004) pp. 73-84.

44. The California Low-Emission Vehicle Regulations for Passenger Cars, Light-Duty Trucks and MediumDuty Vehicles, including all or portions of Sections 1900,
$1956.8,1960.1,1960.5,1961,1961.1,1962,1962.1$, 1965, 1976, 1978, 2062, and 2101, title 13, California Code of Regulations, as of October 11, 2007.

45. U.S. Environmental Protection Agency, Fuel Economy Labeling of Motor Vehicles: Revisions to Improve Calculation of Fuel Economy Estimates, U.S. Environmental Protection Agency Office of Transportation and Air Quality Report EPA420-D-06002. Ann Arbor, MI (Jan. 2006).

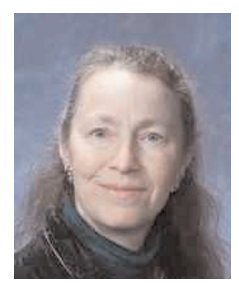

\section{AUTHORS}

Dr. Linda Gaines, a Transportation Systems Analyst in the Technology Analysis Section, works on ways to minimize impacts from transportation, most recently by reducing idling of heavy vehicles. She joined Argonne in 1976 and wrote handbooks of energy and material flows in the petroleum refining, organic chemicals, and copper industries that provided background for studies of issues involved in recycling discarded tires, packaging, and other energy-intensive materials. She has also examined the costs and impacts of production and recycling of advanced-design automobiles, trucks, trains, and batteries. Dr. Gaines holds a B.A. from Harvard and a Ph.D. in Physics from Columbia.

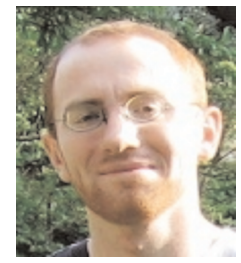

Andrew Burnham is a Fuel and Vehicle Systems Analyst in the Systems Assessment Section. At Argonne, he has been assisting with the update of the Greenhouse Gases, Regulated Emissions, and Energy Use in Transportation (GREET) Model with a focus on developing the GREET 2 vehicle cycle, which examines vehicle material energy use and emissions from "cradle-to-grave". He received his Bachelor's degree in Environmental Engineering from Northwestern University in 2002 and his Master's degree in Transportation Technology and Policy from the University of California, Davis in 2004.

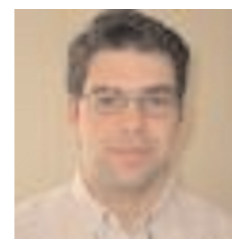

Aymeric Rousseau is head of the Advanced Powertrain Vehicles Modeling Department at Argonne National Laboratory. After working for PSA Peugeot Citroen for several years in the Hybrid Electric Vehicle research department as a modeler, he joined Argonne National Laboratory, where he is now responsible of the development of PSAT, the Powertrain System Analysis Toolkit. He received his engineering diploma at the Industrial System Engineering School in La Rochelle, France in 1997 and a Technology Research Diploma from La Rochelle University based on Hybrid Electric Vehicles modeling in 1999. 


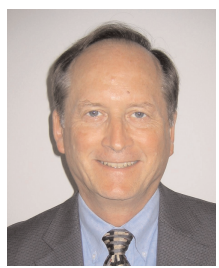

Dr. Danilo Santini is a Senior Economist and Section Leader of the Technology Analysis Section. He has worked at Argonne for 33 years, mostly in assessments of energy and environmental technologies. His section developed models for evaluating costs and benefits of highway transportation technology, including emissions of criteria pollutants and greenhouse gases. Dan has written or contributed to over 150 publications. Since May of 2001, he has been the U.S. Department of Energy's technical representative to the International Energy Agency Implementing Agreement on Electric and Hybrid Vehicles. From 2003-06 he was a member of the American Transportation Research Institute's Research Advisory Committee.

\section{APPENDIX A: \\ SYSTEM-WIDE PHEV INTERACTIONS WITH U.S. ELECTRIC GRID}

Several studies took a very long view, asking what would happen if PHEVs were highly successful over the next few decades $[16,17,20,21,22,23,24]$. The "baseline scenario" of multiple studies - where no carbon constraints were assumed - implied eventual increases in coal generation as a result of PHEVs [20, 22, 23]. However, for two of the U.S. studies that used a power plant dispatch model and either examined the near-term [18], or isolated both near-term and longterm effects [20], the early decade for PHEVs was estimated to involve more natural gas generation than coal generation. Shelby and Mui's estimates projected expanded generation from natural gas combined cycle power plants through 2015, despite no construction of new plants of that type [20]. Kristien, Kohen and Johan estimate in the reference case for Belgium that carbon emissions from PHEVs (relative to HEVs) would be slightly reduced through 2020 , then increase. Relative to conventional vehicles, significant benefits were estimated throughout.

Hadley [18], who used a dispatch model and examined different PHEV charging strategies and rates for the Southeastern U.S., estimated a minimum percentage of coal generation of about $21-23 \%$, and a maximum of $61^{-}$ $63 \%$. The remainder was estimated to be natural gas generation, predominantly via combined cycle power plants. Hadley's estimates, which used realistic models of charging for realistic numbers of PHEVs, may be contrasted with the estimates of Kintner-Meyer et al. [19], where the absolute maximum number of PHEVs that could nominally be put on the grid (orders of magnitude larger than Hadley's realistic estimates) was estimated, without any evolution of the grid. Given the crude estimates of Kintner-Meyer et al., the result for the same region examined by Hadley (the South-East Electric Reliability Council Region), was an estimate of $43 \%$ coal generated power. In the near-term, the regional results of Hadley, the national results of Shelby and Mui, and the regional/national estimates of Kintner-Meyer et al. imply that the effects of the initial small percentages of PHEVs through 2015 is likely to result in a greater use of natural gas than coal, perhaps with the exception of the upper Midwest and Northwest [19].

Though the details of types of generators used are not available, Kristien, Koen and Johan [22] estimate for Belgium a base case improvement of carbon emissions for PHEVs through 2020, then a decrease. Such a pattern would be consistent with early increases in use of natural gas, followed by construction and expansion of use of coal fired units, much like the Shelby and Mui predictions for the U.S.

Several studies recognize that if public policy were to change in such a way that carbon emissions were regulated or taxed and a clean electric generation system emerged, then PHEVs would unequivocally provide a long-term path toward significant reductions of greenhouse gas emissions of light duty vehicles [16, 17, 21, 22, 24]. Those studies that also provide quantitative estimates for the near-term [18, 20, 22] suggest that to begin introduction of PHEVs would be a "no regrets" short term strategy that would reduce greenhouse gases due to the likelihood of a significant proportion of generation coming from natural gas. Reasons for this will be discussed further in section 4.1.1.

Only one study has addressed long term air quality in terms of ambient concentrations of particulates and ozone [23]. This study created estimates for the year 2030, and assumed a very high degree of success of PHEVs which operated all electrically when charge depleting. This study implicitly assumes significant achievements in battery technology and costs beyond our year of interest (2015), such that zero tailpipe emissions of PHEVs can be assured. This study did not assume any carbon policy. It projected expansion of coal generation and shrinking of natural gas generation, as of 2030. This projection is consistent with the projections of Shelby and Mui [20] for years beyond 2015. For 2020 and 2025, Shelby and Mui project significant expansion of coal generating capacity, combined with shrinkage of natural gas generating capacity, as does the Knipping and Duvall study [23].

A very important point about the Shelby and Mui study is that it estimates that a scenario in which $\mathrm{PHEVs}$ replace $\mathrm{HEVs}$ is almost identical in GHG emissions to the HEV scenario [20]. Whether one estimates improvements or demerits when PHEVs replace HEVs is a subject of projections of vehicle attributes and generation mix. If coal without carbon capture and storage (CCS) is assumed to be the source of electricity, then the PHEV is estimated to cause higher emissions than an HEV. However, most analysts 
anticipate a mix of coal and other cleaner generators, leading in most cases beyond 2015 to approximate GHG neutrality between PHEVs and HEVs. Further, as Shelby and Mui point out, if CCS is possible, then the PHEV could eventually be superior to the HEV with respect to potential to reduce GHGs while using the abundant domestic fossil fuel, coal. The study by Knipping and Duvall [23] implies that even if coal is a dominant source of generation, if in the long-run PHEVs can operate all electrically for $32 \mathrm{~km}$ per day, then air quality in nearly all of the U.S. would be improved.

Many of the studies just discussed recognize the possibility that coal will ultimately be the dominant feedstock for future expansion in electric generation. However, prudent planning would also recognize that there is a reasonable chance that carbon control policies using taxes or emissions limits will be implemented in part or all of the United States within the next decade or so. Some studies have examined futures which assume either success in developing low cost, low carbon generation technologies due to $\mathrm{R} \& \mathrm{D}$, or policies designed to create incentives for low carbon generation even if costs do not drop sharply [16, 17, 22, 24]. For three of those four for which we have been able to examine detailed mix projections by year [16, 17, 24], significant expansion of wind generation is projected. In the study by Balash et al. [16], both wind and integrated combined cycle coal generation with carbon capture and storage become significant by 2030 . The study by Short and Denholm [17] is most optimistic about wind, having nuclear and natural gas generation shrink; coal and wind both increase significantly. In this study, natural gas was projected to be a scarce resource, since real prices of natural gas were projected to rise significantly over the study period. The Balash et al. study [16], which also took care to properly simulate the attributes of wind generation, is compositionally similar. As of 2050, the "carbon restrictions" case in the study by Duvall and Knipping [24] also has an dexpanded share of wind. Unlike the prior two studies, it also projects expansion for advanced nuclear and advanced natural gas combined cycle. Integrated combined cycle coal fired generation with CCS also expands, as is the case in Balash et al., and in Short and Denholm. Nevertheless, in the Duvall and Knipping study's carbon constrained case, coal's overall share decreases.

Both Kristien, Koen and Johan [22], and Kromer and Heywood [21] include "clean grid" estimates, illustrating the potential to reduce GHGs considerably in the future in the event that PHEVs succeed.

Obvously, the future is not known. Many pathways are possible. The general consensus among these studies is that the PHEV technology can create an opportunity to choose among several alternative pathways for the electric generation system, many of which would allow greater reduction of GHGs than would HEVs alone.

The studies discussed have in common the reporting of PHEV emissions and energy use on the basis of an estimated annual average. Although the analysts clearly estimate the electricity consumption during the charge depleting (CD) phase of PHEV operation, they then average this back together with the charge sustaining (CS) operation. As Kristien, Koen, and Johan point out, it is difficult to anticipate what portion of PHEV driving will be done in CD vs. CS mode [22]. Vyas et al., in a companion paper, address this complex question [25]. Due in part to the uncertainty about the mix of CD and CS mode of operation of PHEVs, we believe that it is instructive to separate the impact estimates for these two modes. We therefore present separate estimates of CD only operation mode in this paper.

Another implicit assumption in prior studies [10, 11, $12,16-20,22-25]$ is that the CD mode for a PHEV will be all-electric (CDE). More recently, it has been recognized that operation in "blended" mode may be considerably less expensive to implement [21, 25], and quite effective in reducing petrol use. By separating out the CD mode, we are able to get a better idea just how effective the investment in a battery pack for a PHEV can be. We look at the effect of the battery pack only when the extra dollars invested in the PHEV pack (instead of an HEV pack) are used for their intended purpose, which is charge depletion.

In estimates for this paper we retain the conventional assumption that the PHEV operates in CDE. However, we note that tracking of the emissions attributes of blended mode PHEVs (PHEVBs) will be desirable in future research. Nevertheless, we do not regard the omission of PHEVB emissions estimation at this time to be problematic. Vyas et al. include the cost of an electrically heated catalyst for the PHEVs whose costs are estimated [25]. It is anticipated that adequate emissions control strategies can be developed for early PHEVBs. As Kromer and Heywood point out, "because plug-in hybrids will comprise a small fraction of the inuse fleet for many years to come ... the near-term environmental impact is ... marginal.” [21, p. 79].

Our perspective in this paper is to focus on the first few years of introduction of PHEVs into the marketplace. Such vehicles are not likely to be commercially available until 2010. They will not constitute a significant portion of the fleet of vehicles until many years afterwards. Having examined the implications of prior studies of the effects of PHEVs on the grid, we conclude that the early mix of electric generation is likely to include a mix of coal and natural gas power plants, perhaps with some renewable power plants as well. Early PHEVs will likely "do no harm", in a policy neutral environment, and will probably often provide considerable benefit per PHEV sold, even if the total early effects will be small. 
Between now and 2010 there will be opportunity to contemplate the near-term attributes of first generation PHEVs and the generators that will serve them, and develop interim public policy in light of the technical trade-offs that are identified. Beyond the anticipated 2010 introduction of PHEVs, the relative success of emerging advanced electric generation technology options will become more apparent, as will the marketability of the PHEVs themselves. Thus, there is time to watch and wait as the R\&D on battery and hybrid powertrain technology enhances opportunities and enlightens industry and customers concerning the most effective way to implement the technology.

\section{APPENDIX B: \\ DEFINITIONS, ACRONYMS, AND FUEL CONSUMPTION ESTIMATION}

Powertrain descriptors:

ICE = internal combustion engine

$\mathrm{SI}=$ spark ignited

$\mathrm{CI}=$ compression ignited (associated with LSD and GTL)

$\mathrm{DI}=$ direct injection

$\mathrm{FC}=$ fuel cell

Battery types:

$\mathrm{NiCd}=$ nickel cadmium (a battery chemistry previously seriously considered for $\mathrm{EVs}$ )

$\mathrm{Ni} \mathrm{MH}=$ nickel metal hydride (a battery chemistry used in existing $\mathrm{HEV}_{\mathrm{s}}$ )

Li-ion = lithium ion (a "family" of battery chemistries candidates for future $\mathrm{HEV}$ s and $\mathrm{PHEV}$ )

Fuel types:

$\mathrm{RFG}=$ reformulated gasoline/petrol (refined petroleum product)

$\mathrm{CG}=$ conventional gasoline/petrol (refined petroleum product)

LSD $=$ low sulfur diesel (refined petroleum product)

$\mathrm{CNG}=$ compressed natural gas

GTL = natural gas-to-liquids (product is very low sulfur diesel)

$\mathrm{GH} 2$ = natural gas converted to hydrogen, stored under compression.

$\mathrm{CTL}=$ coal-to-liquids (product is low sulfur diesel fuel)

Driving Cycles or Driving Behavior Identifiers [45], Relation to Estimates in this Paper:

Fuel economy $=$ form of providing information to U.S. consumers, distance per unit of fuel used

Fuel consumption $=$ fuel per unit distance moved, form presented and used in this paper

UDDS = urban dynamometer driving schedule, lasting 1372 seconds, constituting $\sim 12 \mathrm{~km}$, and averaging $\sim 31 \mathrm{~km} / \mathrm{h}$ (used in U.S. new vehicle emissions \& fuel economy certification test - federal test procedure [FTP])

HWY = Highway driving cycle, lasting 765 seconds, constituting $16.3 \mathrm{~km}$, and $77.1 \mathrm{~km} / \mathrm{h}$ (used in U.S. new vehicle fuel economy certification tests, but not emissions tests).

Cold start $=$ start of a vehicle that has been parked for hours, leads to high emissions per second until the catalyst and engine warm up. Also increases fuel consumption significantly.

Warm start = start of a vehicle that has been parked for minutes

Hot start $=$ start of a vehicle than has been off for seconds

FTP = by FTP here we mean the federal test procedure used to measure emissions, from which an estimate of "city" fuel economy is also constructed. The FTP involves running a complete UDDS, starting with a cold start, turning the engine off for ten minutes, restarting warm and running the first 505 seconds of the UDDS again. The running time for the UDDS is 1372 seconds. The running time for the FTP is 1877 seconds (ignoring the ten minutes with engine off). The average weighted speed of the FTP is $34 \mathrm{~km} / \mathrm{h}$, while the average speed for the UDDS is $31 \mathrm{~km} / \mathrm{h}$ [11].

US06 = a driving cycle more aggressive than most U.S. drivers drive, lasting 600 seconds, constituting 12.8 $\mathrm{km}$, and averaging $77 \mathrm{~km} / \mathrm{h}$. Top speed, acceleration rates and deceleration rates are all considerably higher than for the HWY cycle.

Certification fuel economy (U.S.) = a weighted geometric mean of the FTP and HWY.

Old window sticker fuel economy (U.S.) = weighted average of FTP x 0.9; HWY x 0.78

City window sticker fuel economy $=$ FTP $\times 0.9$ (consumer information number until 2007)

Highway window sticker fuel economy $=$ HWY $\times 0.78$ (information number until 2007)

New window sticker fuel economy $=$ a weighted average of several driving tests, using information from tests using the UDDS, HWY, US06, and other driving cycles. Resulting fuel consumption is higher than the inverse of the old window sticker value(s). Both city and highway values are estimated, as well as a weighted average of the two - the combined cycle).

On-road fuel consumption $=$ Estimates of the inverse of new window sticker fuel economy constructed in this paper, from PSAT vehicle simulations [29] of UDDS (hot, no cold or warm starts) and HWY fuel consumption. The on-road fuel consumption penalty was estimated with a statistical model of the relationship of the (1) inverse of new window sticker fuel economy to the (2) inverse of certification fuel economy, for U.S. HEVs, diesels and same make and model SI ICEs. Hot UDDS simulations were scaled up to estimated FTP certification values before adding the statistical estimates of the on-road fuel consumption penalty. Thus, petrol, diesel and HEV on-road fuel consumption penalties are based on a statistical summary of EPA dynamometer tests. Estimates for PHEV CD operation and FCVs are relatively less certain. 
Vehicle Types Simulated in this Study:

ICE $=$ engine type used in conventional powertrains, either SI, or CI

$\mathrm{HEV}=$ hybrid electric vehicle (always SI in this paper)

PHEV = plug-in hybrid (always SI in this paper)

PHEVXX = where "XX" is filled in by a number of kilometers of all electric range nominally obtainable on a certification test. California has specified a test for certification of all electric range capability which requires that the vehicle be able to operate all electrically while meeting the speed and acceleration requirements of the UDDS. This is not an official terminology, but has become common practice in the U.S. "XX" defines the distance that can be traveled when a battery is discharged from full to a selected SOC. Simulations for this research assume $30 \%$. This research investigated by simulation PHEV16, PHEV32 and PHEV64 vehicles. The electric range requirement is based on the ability to run the UDDS.

$\mathrm{FCV}=$ fuel cell vehicle (powered by compressed hydrogen)

Two fundamentally different PHEV operating/control strategies:

$\mathrm{CS}=$ charge sustaining (the state-of-charge of the battery does not vary significantly, used in HEV and PHEV)

$\mathrm{CD}=$ charge depleting (the state-of-charge of the battery declines until the battery is nearly discharged, used in PHEVs only). 